\title{
3 Research Square

\section{Statistical characteristics of the spatial distribution of wind and snow in the Xinjiang Uygur Autonomous Region}

\section{Xuetao Yu ( $\square$ yuxuetaoxiaoping@163.com )}

Shijiazhuang Tiedao University https://orcid.org/0000-0002-8466-5653

Mengke Liu

Shijiazhuang Tiedao University

Junyu Wang

Shijiazhuang Tiedao University

Qingkuan Liu

Shijiazhuang Tiedao University

Jianqing Bu

Shijiazhuang Tiedao University

\section{Research Article}

Keywords: the Xinjiang Uygur Autonomous Region, snowdrift, spatial distribution, daily data sets of climate data for the China international surface exchange station

Posted Date: February 17th, 2021

DOI: https://doi.org/10.21203/rs.3.rs-233920/v1

License: (c) (1) This work is licensed under a Creative Commons Attribution 4.0 International License. Read Full License

Version of Record: A version of this preprint was published at Natural Hazards on January 10th, 2022. See the published version at https://doi.org/10.1007/s11069-021-05127-4. 


\title{
and snow in the Xinjiang Uygur Autonomous Region
}

\author{
Xuetao $\mathrm{Yu}^{1-3}$ Mengke Liu ${ }^{3}$ Junyu Wang ${ }^{3}$ Qingkuan Liu*1,4,5 Jianqing $\mathrm{Bu}^{* 1-3}$ \\ 1-(State Key Laboratory of Mechanical Behavior and System Safety of Traffic Engineering Structures, \\ Shijiazhuang Tiedao University, Shijiazhuang 050043, P. R. China) \\ 2-(Key Laboratory of Traffic Safety and Control of Hebei Province, Shijiazhuang 050043, P. R. China) \\ 3-(School of Traffic and Transportation, Shijiazhuang Tiedao University, Shijiazhuang 050043, P. R. China) \\ 4-(Wind Engineering Research Center, School of Civil Engineering, Shijiazhuang Tiedao University, Shijiazhuang \\ 050043, P. R. China) \\ 5-(Innovation Center for Wind Engineering and Wind Energy Technology of Hebei Province, Shijiazhuang \\ 050043, P. R. China)
}

\begin{abstract}
At present, the wind and snow loads are calculated independently when determining the design specifications for building structures. Yet, when snow drifting occurs, the basic wind and snow pressures exist almost simultaneously. Therefore, building specifications based on the independent calculations of the wind and snow loads cannot be used effectively in areas that are severely impacted by snow drifting. Some parts of the Xinjiang Uygur Autonomous Region of China have suffered particularly severe snow drifting natural disasters. In this paper, we offer an analysis of the statistical characteristics of the spatial distribution of wind and snow in this region. In particular, we extract the values of the combined distribution of the wind and snowfall in the Xinjiang Uygur Autonomous Region of China by using parameters such as snowfall intensity, snowfall amount, wind speed, and wind direction as indicators that show the snow drifting disasters. This study found that, after heavy snowfall events, the accumulative wind scale is high and the accumulative snowfall is large in the Altay, the Bortala Mongol Autonomous, and the Tacheng Prefectures of northern Xinjiang, and the Kizilsu Kirghiz Autonomous Prefecture of western Xinjiang. It has an important practical significance for the design of building structures and the treatment of snow drifting disasters.
\end{abstract}

Keywords: the Xinjiang Uygur Autonomous Region; snowdrift; spatial distribution; daily data sets of climate data for the China international surface exchange station

\section{Introduction}

A snow drifting disaster is one of many types of snow damage that occurs frequently in northern provinces of China like the Xinjiang Uygur Autonomous Region, the Inner Mongolia Autonomous Region, the Jilin Province and so on. This type of disaster consists of deep drifts of snow which may close roads or simply block traffic. In severe cases, it can result in the structural damage to buildings, the collapse of roofs and houses, and other problems which disrupt the daily lives of the inhabitants, as well as industrial and agricultural production. For example, the biggest snowstorm on record occurred in Liaoning Province of China in March 2007. For the most part, it halted traffic; it forced airports and expressways to close, and stopped several of the trains - and this caused huge economic losses to the Liaoning Province(Li, Zhu et al. 2007). Since January 10 of 2008, southern

${ }^{*}$ Corresponding author 1 address: Qingkuan Liu, Wind Engineering Research Center, School of Civil Engineering, Shijiazhuang Tiedao University, 17 Northeast, Second Inner Ring, Shijiazhuang, Hebei, P.R.C. 050043. E-mail: lqk@stdu.edu.cn

Corresponding author 2 address: Jianqing Bu, School of Traffic and Transportation, Shijiazhuang Tiedao University, 17 Northeast, Second Inner Ring, Shijiazhuang, Hebei, P.R.C. 050043. E-mail: bujq2004@163.com 
China suffered a heavy snow and sleet natural disaster which was the worst in 50 years. More than 20 of China's provinces were affected. The snow and ice storms cut off travel by road and rail, and cost 151.65 billion yuan in direct economic losses(Chen and Fan 2009). In January 2010, the Altay district, the Tacheng district and other places nearby in the Xinjiang Uygur Autonomous Region suffered a once-in-60-year blizzard disaster that closed off the main access roads of the city of Tacheng, and caused direct economic losses of 650 million yuan. The snowfall intensity, duration, and amount of rainfall (or snowfall) for this event have rarely been seen in modern Chinese history(Liu, Liu et al. 2010).

Generally, snowdrift formation is a joint probability event of wind and snow variables, with the two primary variables being snowfall intensity and wind strength. Only when heavy snowfall and strong winds appear together will snowdrifts be formed(Zha, Yu et al. 2012). In the Load Code for the Design of Building Structure, the wind and snow loads are calculated separately. So, the calculated load based on this load standard cannot be used to design safe architectural structures for those areas that are affected by snow drifting disasters(Research, University et al. 2012).

Snow drifting disasters have a serious impact on the inhabitants of colder regions. Aiming at this problem, many scholars have studied the formation and prevention of snow drifting disasters. Guoping Su has studied the causes of snow drifting disaster, and the factors that influence it. More particularly, Su has analyzed the load status of the snow particles and proposed the design parameters of a retaining wall(Su 2017). Chengliang Ying has studied the technology of the prevention and cure of a snow drifting disaster on highways(Ying 2007). Having studied the causes of snow drifting disasters on the highways in the Xinjiang Uygur Autonomous Region, Jian Liu et al. have summarized the main types of snow deposition on the region's highways, including windward snow cover, leeward snow cover, curve flow snow, cutting snow, and high embankment snow types(Liu, Yao et al. 2008). Tingliang Wang implemented the numerical simulation of snow disasters to sum up the drifting snow disaster prevention technology of the railway. He pointed out that, in general, three conditions are required for the formation of a drifting snow disaster: the source of sufficient snow, the wind which can sweep the snow grains, and the landform which can help to decrease the accumulation of snow grains(Wang 2009). Therefore, in this paper, the authors studied the joint distribution of wind and snow in the Xinjiang Uygur Autonomous Region by using a mass of historical meteorological data, and summarized the distribution rules of wind and snow in Xinjiang, thereby providing a guide for the prevention and control of future snow drifting disasters in the Xinjiang Uygur Autonomous Region which, in turn, provides significant guidance on the construction and maintenance of the transportation infrastructure in the region.

\section{Meteorological data}

The meteorological data used in this study is the "Daily Data Sets of Climate Data for China International Surface Exchange Station (V3.0)". It includes eight major items, including the daily air pressure values, air temperature, precipitation, evaporation, relative humidity, wind, sunshine time, and $0 \mathrm{~cm}$ ground temperature. Beginning in January 1951, the data was acquired daily from 824 basic meteorological stations located in China. After effective quality control, the availability rate of the meteorological factor data was, in general, more than $99 \%$, and the accuracy rate was nearly $100 \%$.

In this study, the precipitation and wind data were selected from the above data sets. In the precipitation data, the accumulated precipitation from 20:00 of the previous day to 20:00 was used. In the wind data, the average wind speed, the maximum wind speed, and the direction of maximum 
wind speed were used. Under normal circumstances, the daily average wind speed was obtained by calculating the average of four values observed at 02:00, 08:00, 14:00, and 20:00. However, when the observation station was not equipped at with a self-recording instrument, the daily average wind speed is the average of the three wind speed values observed at 08:00, 14:00, and 20:00. Maximum wind speed refers to the average maximum wind speed over 10 minutes during a given period. The wind direction was expressed relative to 16 azimuths. The representation directions were N, NNE, NE, ENE, E, ESE, SE, SSE, S, SSW, SW, WSW, W, WNW, NW, and NNW. The absence of wind was also recorded.

As there was no distinction between rainfall and snowfall in the data sets, the precipitation over the whole winter period was used to represent snowfall in our analysis of the statistical characteristics of snow and wind. The winter period is defined as the months of January, February, March, November, and December. After importing the above data into a database, the effective data from 64 observation stations in the Xinjiang Uygur Autonomous Region were selected for this analysis. The location and number of the 64 stations are shown in Figure 1. The selected period was from 1968 to 2016 and included a total of 7412 days. There was a lack of observation data for a portion of this time due to force majeure. However, the number of missing days at some sites was very small. Station 51704 had no data for 25 days, which comprised the greatest number of days with no data among all the stations. For this situation, the missing data were inferred based on the mean of the data measured before and after the gap.

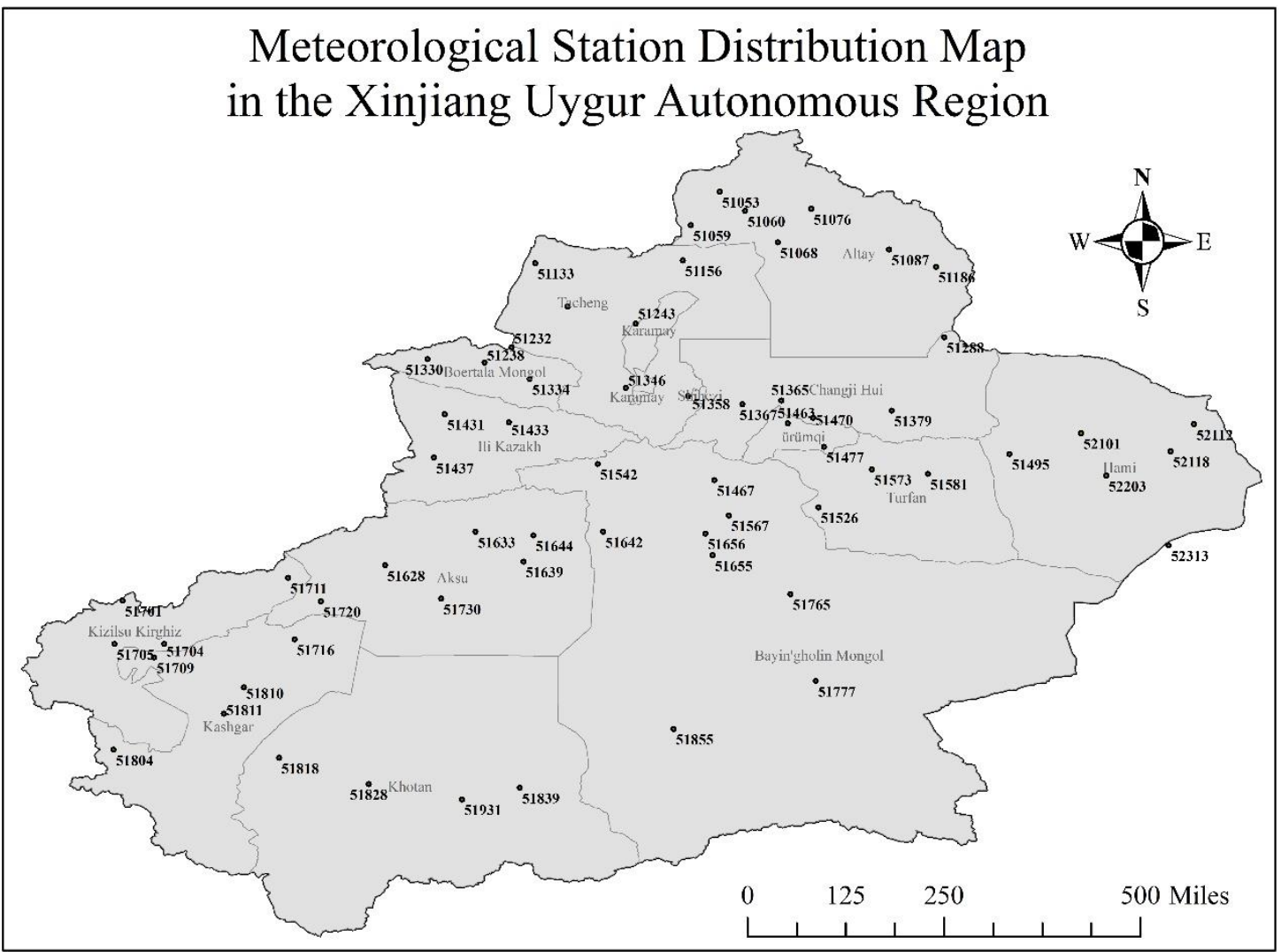

Figure 1. Meteorological station distribution map in the Xinjiang Uygur Autonomous Region.

\section{Wind scale distribution in winter}

In the field of meteorological forecasting, the wind scale of a certain day is divided into 18 classes according to the average wind speed. The basis of the classification is the "Wind Scale"(Centre 2012). The specific classification method is shown in Table 1(Centre 2012). According to this 
108

109

110

111

method, the appearance frequency of different daily wind scales at 64 stations in the Xinjiang Uygur Autonomous Region was extracted over the periods of 1st, 2nd, 3rd, 11th, and 12th months from 1968 to 2016. The specific results are shown in Table 2.

Table 1. Wind scale classification.

\begin{tabular}{|l|l|l|l|l|l|}
\hline Wind scale & Wind speed $(\mathrm{m} / \mathrm{s})$ & Wind scale & Wind speed $(\mathrm{m} / \mathrm{s})$ & Wind scale & Wind speed $(\mathrm{m} / \mathrm{s})$ \\
\hline 0 & $0.0 \sim 0.2$ & 6 & $10.8 \sim 13.8$ & 12 & $32.7 \sim 36.9$ \\
\hline 1 & $0.3 \sim 1.5$ & 7 & $13.9 \sim 17.1$ & 13 & $37.0 \sim 41.4$ \\
\hline 2 & $1.6 \sim 3.3$ & 8 & $17.2 \sim 20.7$ & 14 & $41.5 \sim 46.1$ \\
\hline 3 & $3.4 \sim 5.4$ & 9 & $20.8 \sim 24.4$ & 15 & $46.2 \sim 50.9$ \\
\hline 4 & $5.5 \sim 7.9$ & 10 & $24.5 \sim 28.4$ & 16 & $51.0 \sim 56.0$ \\
\hline 5 & $8.0 \sim 10.7$ & 11 & $28.5 \sim 32.6$ & 17 & $\geq 56.1$ \\
\hline
\end{tabular}

112 Table 2. Appearance frequency of different daily wind scales in the Xinjiang Uygur Autonomous Region during the period of 1st, 2nd, 3rd, 11th, and 12th months from 1968 to 2016.

\begin{tabular}{|c|c|c|c|c|c|c|c|c|c|c|c|c|}
\hline $\begin{array}{l}\text { Station } \\
\text { ID }\end{array}$ & $\begin{array}{r}\text { Wind } \\
\text { scale } \\
0\end{array}$ & $\begin{array}{r}\text { Wind } \\
\text { scale } \\
1\end{array}$ & $\begin{array}{l}\text { Wind } \\
\text { scale } 2\end{array}$ & $\begin{array}{l}\text { Wind } \\
\text { scale } 3\end{array}$ & $\begin{array}{l}\text { Wind } \\
\text { scale } 4\end{array}$ & $\begin{array}{l}\text { Wind } \\
\text { scale } 5\end{array}$ & $\begin{array}{l}\text { Wind } \\
\text { scale } 6\end{array}$ & $\begin{array}{l}\text { Wind } \\
\text { scale } 7\end{array}$ & $\begin{array}{l}\text { Wind } \\
\text { scale } 8\end{array}$ & $\begin{array}{l}\text { Wind } \\
\text { scale } 9\end{array}$ & $\begin{array}{r}\text { Wind } \\
\text { scale } \\
10\end{array}$ & $\begin{array}{r}\text { Wind } \\
\text { scale } \\
11\end{array}$ \\
\hline 51358 & 952 & 4673 & 1650 & 107 & 7 & 0 & 0 & 0 & 0 & 0 & 0 & 0 \\
\hline 51367 & 65 & 3020 & 3808 & 488 & 29 & 1 & 0 & 0 & 0 & 0 & 0 & 0 \\
\hline 51059 & 56 & 2360 & 3366 & 1175 & 316 & 104 & 27 & 5 & 0 & 0 & 0 & 0 \\
\hline 52112 & 193 & 1591 & 3189 & 1362 & 640 & 263 & 120 & 45 & 6 & 1 & 0 & 0 \\
\hline 51060 & 118 & 714 & 2242 & 2270 & 1415 & 574 & 74 & 4 & 0 & 0 & 0 & 0 \\
\hline 51720 & 166 & 5604 & 1522 & 104 & 15 & 1 & 0 & 0 & 0 & 0 & 0 & 0 \\
\hline 51639 & 732 & 4594 & 1894 & 165 & 25 & 2 & 0 & 0 & 0 & 0 & 0 & 0 \\
\hline 51655 & 446 & 4492 & 2215 & 212 & 31 & 6 & 1 & 0 & 0 & 0 & 0 & 0 \\
\hline 51704 & 663 & 5655 & 869 & 153 & 40 & 5 & 2 & 0 & 0 & 0 & 0 & 0 \\
\hline 51818 & 211 & 4957 & 2119 & 116 & 9 & 0 & 0 & 0 & 0 & 0 & 0 & 0 \\
\hline 51730 & 332 & 5346 & 1570 & 145 & 17 & 1 & 0 & 0 & 0 & 0 & 0 & 0 \\
\hline 51433 & 180 & 3804 & 2765 & 537 & 97 & 18 & 1 & 0 & 0 & 0 & 0 & 0 \\
\hline 51526 & 12 & 2335 & 4725 & 309 & 30 & 1 & 0 & 0 & 0 & 0 & 0 & 0 \\
\hline 52118 & 32 & 1289 & 4075 & 1505 & 405 & 87 & 18 & 1 & 0 & 0 & 0 & 0 \\
\hline 51633 & 975 & 6104 & 313 & 13 & 2 & 2 & 0 & 0 & 0 & 0 & 0 & 0 \\
\hline 51701 & 158 & 1877 & 3165 & 1634 & 497 & 70 & 9 & 0 & 0 & 0 & 0 & 0 \\
\hline 51642 & 1273 & 4477 & 1557 & 98 & 4 & 1 & 0 & 0 & 0 & 0 & 0 & 0 \\
\hline 51365 & 669 & 4538 & 2070 & 129 & 6 & 0 & 0 & 0 & 0 & 0 & 0 & 0 \\
\hline 51470 & 34 & 966 & 5338 & 1008 & 57 & 3 & 1 & 1 & 0 & 0 & 0 & 0 \\
\hline 51656 & 204 & 3420 & 2858 & 686 & 196 & 41 & 7 & 0 & 0 & 0 & 0 & 0 \\
\hline 51330 & 341 & 4569 & 2252 & 214 & 27 & 6 & 1 & 0 & 0 & 0 & 0 & 0 \\
\hline 51238 & 673 & 4948 & 1661 & 122 & 4 & 0 & 0 & 0 & 0 & 0 & 0 & 0 \\
\hline 51068 & 253 & 3004 & 3109 & 866 & 153 & 18 & 9 & 0 & 0 & 0 & 0 & 0 \\
\hline 51053 & 61 & 968 & 1959 & 2066 & 1551 & 642 & 157 & 7 & 0 & 0 & 0 & 0 \\
\hline 51542 & 455 & 3614 & 2182 & 673 & 344 & 122 & 22 & 0 & 0 & 0 & 0 & 0 \\
\hline 51467 & 214 & 2987 & 3864 & 325 & 20 & 2 & 0 & 0 & 0 & 0 & 0 & 0 \\
\hline 51186 & 2822 & 4063 & 466 & 38 & 2 & 1 & 0 & 0 & 0 & 0 & 0 & 0 \\
\hline
\end{tabular}




\begin{tabular}{|c|c|c|c|c|c|c|c|c|c|c|c|c|}
\hline 51288 & 88 & 2628 & 3908 & 695 & 87 & 4 & 1 & 0 & 0 & 0 & 0 & 0 \\
\hline 51810 & 899 & 4727 & 1587 & 163 & 20 & 2 & 0 & 0 & 0 & 0 & 0 & 0 \\
\hline 51804 & 1109 & 3730 & 1939 & 536 & 88 & 7 & 1 & 0 & 0 & 0 & 0 & 0 \\
\hline 51765 & 368 & 4470 & 2083 & 374 & 97 & 17 & 3 & 0 & 0 & 0 & 0 & 0 \\
\hline 51711 & 6 & 1316 & 4624 & 1373 & 91 & 1 & 0 & 0 & 0 & 0 & 0 & 0 \\
\hline 51839 & 121 & 4933 & 2218 & 128 & 8 & 0 & 0 & 0 & 0 & 0 & 0 & 0 \\
\hline 52101 & 834 & 2994 & 2623 & 749 & 201 & 10 & 1 & 0 & 0 & 0 & 0 & 0 \\
\hline 51243 & 506 & 4127 & 2070 & 446 & 159 & 77 & 19 & 4 & 2 & 1 & 0 & 0 \\
\hline 51241 & 100 & 2785 & 3771 & 630 & 118 & 6 & 0 & 0 & 0 & 0 & 0 & 0 \\
\hline 51232 & 47 & 1077 & 2696 & 1774 & 852 & 454 & 332 & 141 & 36 & 3 & 0 & 0 \\
\hline 51477 & 0 & 241 & 1273 & 2110 & 2060 & 1140 & 483 & 86 & 19 & 0 & 0 & 0 \\
\hline 51931 & 126 & 5321 & 1909 & 54 & 2 & 0 & 0 & 0 & 0 & 0 & 0 & 0 \\
\hline 51705 & 837 & 3967 & 1501 & 643 & 348 & 93 & 22 & 1 & 0 & 0 & 0 & 0 \\
\hline 51087 & 2546 & 3907 & 673 & 215 & 60 & 7 & 2 & 0 & 0 & 0 & 0 & 0 \\
\hline 51855 & 343 & 3982 & 2646 & 385 & 53 & 3 & 0 & 0 & 0 & 0 & 0 & 0 \\
\hline 51437 & 161 & 4284 & 2517 & 369 & 77 & 4 & 0 & 0 & 0 & 0 & 0 & 0 \\
\hline 51076 & 687 & 4068 & 2131 & 443 & 71 & 11 & 1 & 0 & 0 & 0 & 0 & 0 \\
\hline 51156 & 632 & 4156 & 1907 & 425 & 214 & 56 & 19 & 3 & 0 & 0 & 0 & 0 \\
\hline 51811 & 367 & 5213 & 1723 & 99 & 10 & 0 & 0 & 0 & 0 & 0 & 0 & 0 \\
\hline 51628 & 106 & 5373 & 1850 & 72 & 9 & 1 & 0 & 0 & 0 & 0 & 0 & 0 \\
\hline 51133 & 66 & 3370 & 3165 & 612 & 154 & 37 & 6 & 1 & 0 & 0 & 0 & 0 \\
\hline 51346 & 189 & 4755 & 2233 & 221 & 13 & 0 & 0 & 0 & 0 & 0 & 0 & 0 \\
\hline 51777 & 68 & 3126 & 3404 & 607 & 153 & 38 & 12 & 1 & 0 & 0 & 0 & 0 \\
\hline 51828 & 73 & 3719 & 3479 & 134 & 6 & 1 & 0 & 0 & 0 & 0 & 0 & 0 \\
\hline 51716 & 881 & 4453 & 1739 & 300 & 38 & 1 & 0 & 0 & 0 & 0 & 0 & 0 \\
\hline 51334 & 495 & 5117 & 1539 & 207 & 45 & 4 & 0 & 0 & 0 & 0 & 0 & 0 \\
\hline 51495 & 357 & 1568 & 2011 & 1174 & 965 & 712 & 315 & 167 & 97 & 40 & 5 & 1 \\
\hline 52313 & 2 & 214 & 2615 & 3396 & 888 & 233 & 51 & 9 & 2 & 0 & 0 & 0 \\
\hline 51431 & 222 & 4704 & 2178 & 273 & 28 & 4 & 1 & 0 & 0 & 0 & 0 & 0 \\
\hline 51573 & 1328 & 5422 & 636 & 22 & 2 & 2 & 0 & 0 & 0 & 0 & 0 & 0 \\
\hline 51567 & 695 & 4364 & 2049 & 268 & 31 & 4 & 0 & 0 & 0 & 0 & 0 & 0 \\
\hline 51379 & 31 & 1207 & 4923 & 1169 & 78 & 3 & 0 & 0 & 0 & 0 & 0 & 0 \\
\hline 51463 & 94 & 3325 & 3670 & 275 & 31 & 12 & 5 & 0 & 0 & 0 & 0 & 0 \\
\hline 52203 & 211 & 4161 & 2757 & 248 & 28 & 7 & 0 & 0 & 0 & 0 & 0 & 0 \\
\hline 51709 & 283 & 4984 & 2008 & 110 & 24 & 3 & 0 & 0 & 0 & 0 & 0 & 0 \\
\hline 51644 & 134 & 3818 & 3297 & 149 & 14 & 0 & 0 & 0 & 0 & 0 & 0 & 0 \\
\hline 51581 & 592 & 5322 & 1431 & 63 & 2 & 0 & 0 & 0 & 0 & 0 & 0 & 0 \\
\hline
\end{tabular}

From Table 2, we know that strong winds appeared frequently at stations 51059, 52112, 51060, 51053, 51232, 51477, 51495 and 52313. As shown in Table 1, the wind speed at the different grades of wind scale was approximately equal to a mathematical progression. For the convenience of making calculations, we multiplied the different wind scales and their corresponding appearance frequency for every station, and then carried the accumulation. Based on this method, the accumulative wind scale distribution map can be obtained if the contemporaneous data from the 
nearby regional sites are added during the calculation process. Taking station 52112 as an example, the total number of days with valid data were 7412 . According to the valid data, the nominal accumulative wind grade was $0 \times 193+1 \times 1591+2 \times 3189+3 \times 1362+4 \times 640+5 \times 263+6 \times 120+7 \times 45+8 \times 6+9 \times 1=17022$, and its average wind scale was about 2.29717. Due to the absence of data for two days, the weighted cumulative wind scale calculated in this study was $17022+2.29717 \times 2=17026.5943$. After this calculation, the final distribution map representing the weighted accumulative wind scale was generated, as shown in Figure 2.



Figure 2. Distribution map of the weighted accumulative wind scale in the Xinjiang Uygur Autonomous Region.

It can be seen from Figure 2 that the weighted accumulated wind scale is large in the northwest of Altay, the east and west of Hami, and at the junction of Urumqi and Turpan. However, it is relatively small in other regions. The Altay region is known as one of the nine strong wind regions in Xinjiang, and it is a typical terrain named "a valley between two mountains", which is composed of the Altay and Saur Mountains, and the Irtysh River Valley. For this reason, the weighted accumulated wind scale in this region is large. The junction of Urumqi and Turpan lies between the middle and the southern Tianshan Mountains. This place is called the Daban Town wind region and is also well known as one of the nine strong wind regions in Xinjiang. It's the key airflow channel between north and south Xinjiang. The development and construction conditions regarding wind energy in this area is the best among the nine strong wind regions. The special terrain in the Hami area is called the "four mountains lock three basins," where cold air activity is frequent. So, the wind scale is high in this area.

Meanwhile, the authors extracted the maximum wind direction data for all the stations in Xinjiang during this period, and drew the wind rose maps of the stations with high wind scales (including 
51053, 51059, 51060, 51232, 51477, 51495, 52112 and 52313). They are shown in Figure 3. The results show that the east wind prevails in the northwest of Altay. The southeast and west winds prevail at the junction of Urumqi and Turpan, and in the southwest corner of Tacheng city. The north wind prevails in the west of Hami city, while the west and east winds prevail in the east.

148

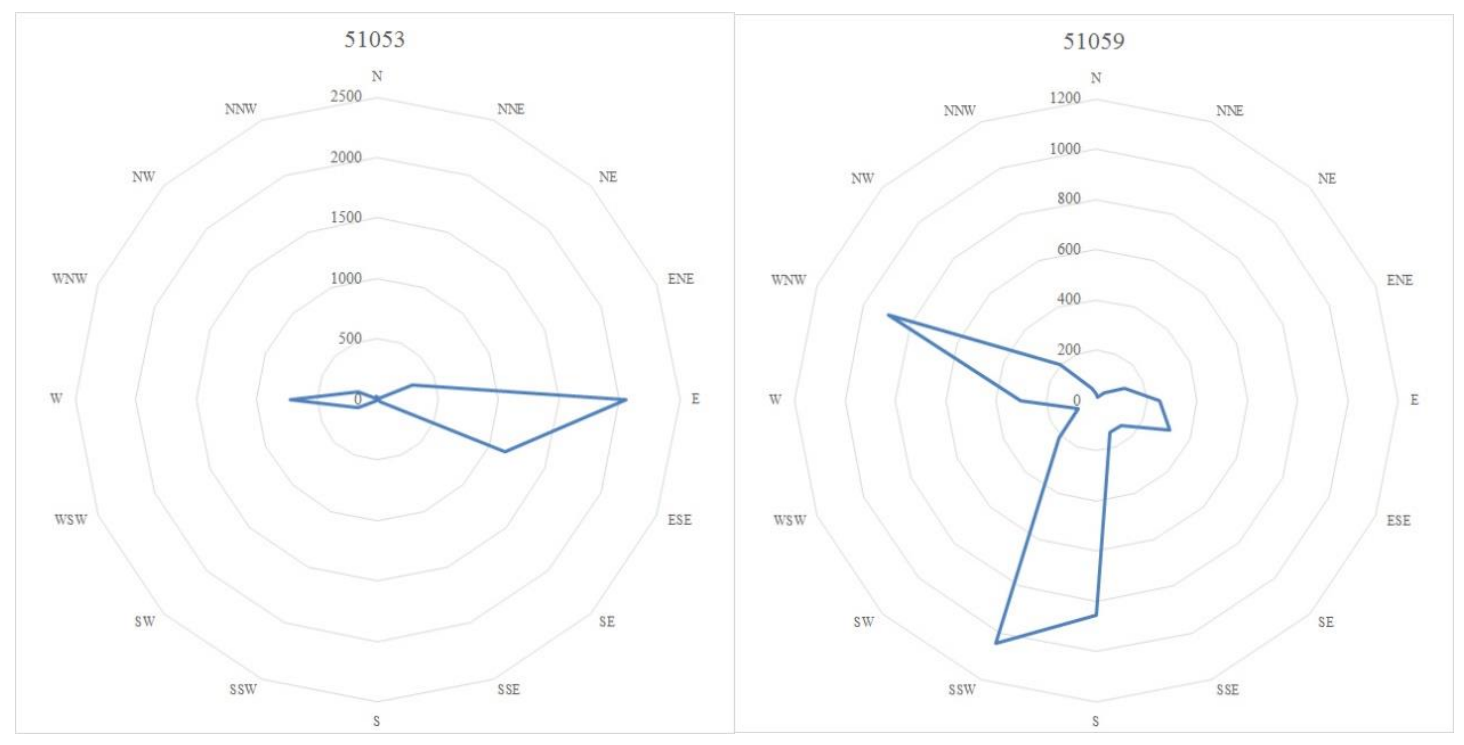

149

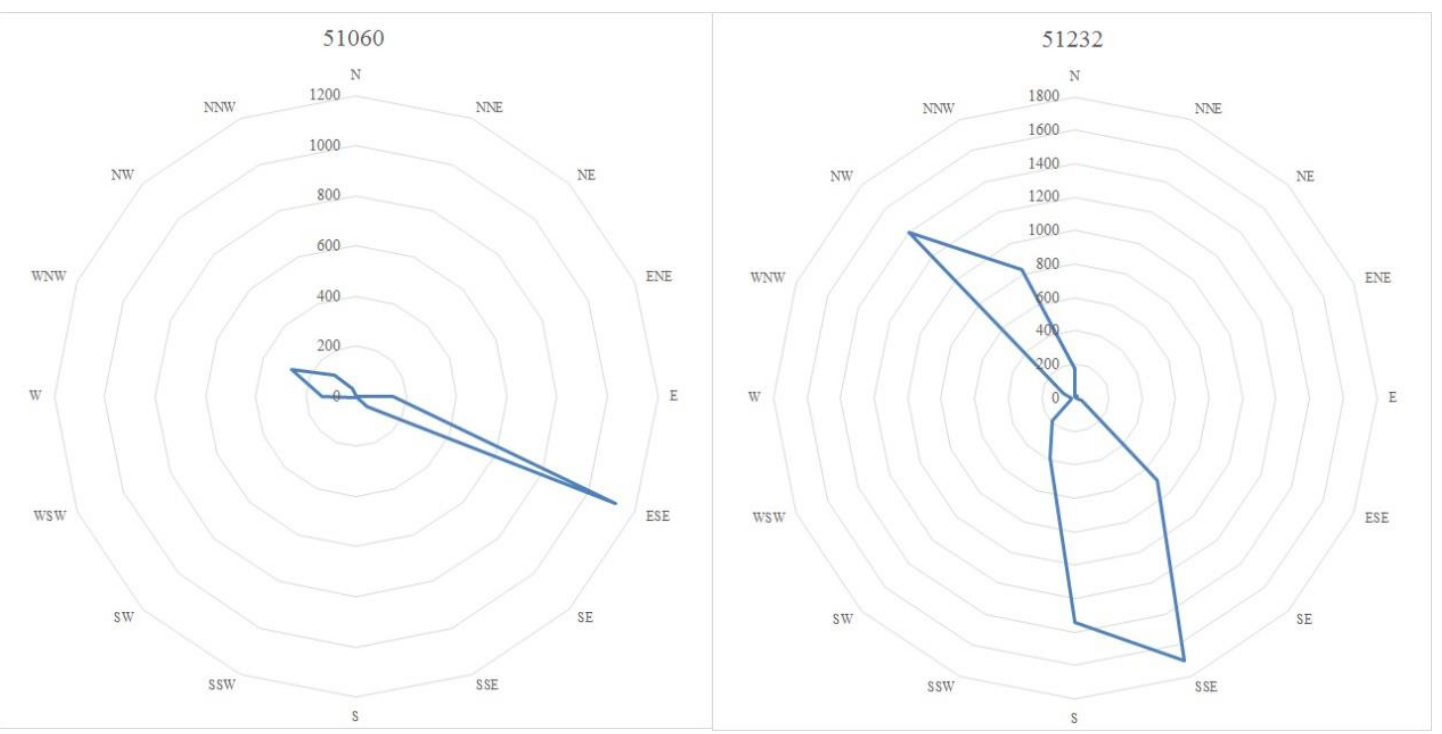



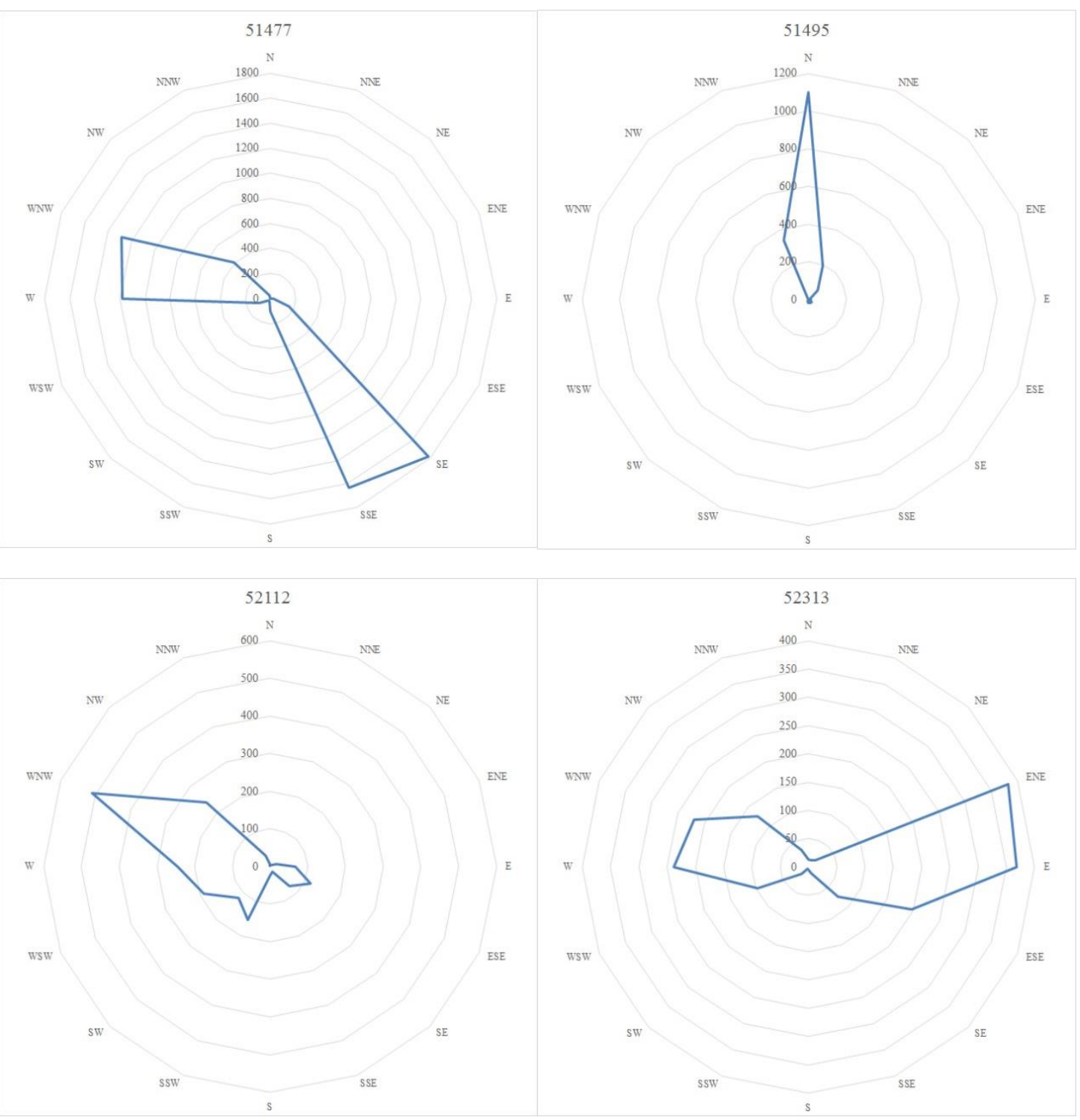

Figure 3. Maximum wind direction rose diagrams for some stations in the Xinjiang Uygur Autonomous Region.

\section{Basic wind speed in winter}

In China's design specifications for buildings that deal with wind load, the reoccurrence period of wind load for general structures is set at 50 years. Therefore, it is important to calculate the reoccurrence period of wind and snow accurately. Consequently, the annual maximum wind speed in winter during the 49-year period was extracted. For historical reasons, this data for the years 1968 , 1969, and 1970 for all the stations in this region are missing. In addition, the data for station 54618 in the year 1971 and for station 54606 for the years 1971 and 1972 are also absent.

160 Based on the above available data, the basic wind speed in the reoccurrence period of 50 and 100 years was calculated using a Gumbel curve with an extreme type I distribution. The calculation steps are as follows.

163 First, the average maximum wind speed $\bar{v}_{i}$ and its root variance $\sigma_{i}$ within a specified period

164 of each station were calculated. The calculation formula $\bar{v}_{i}$ for station number $i$ is shown in 
165

166

equation (1). The formula $\sigma_{i}$ for station number $i$ is shown in equation (2). $v_{i j}$ is the maximum wind speed for station number $i$ in the winter of the year $j$, and $n$ is the year from 1971 to 2016 for most stations.

$$
\bar{v}_{i}=\sum_{j=1}^{n} v_{i j}
$$

$$
\sigma_{i}=\sqrt{\frac{\sum_{j=1}^{n}\left(v_{i j}-\bar{v}_{i}\right)^{2}}{n-1}}
$$

Second, the assurance rate $P$ (according to the recurrence period $T$ ) was obtained. The calculation formula for $P$ is shown in equation (3). The value of $T$ was set to 50 and 100 years.

$$
P=1-\frac{1}{T}
$$

Based on the assurance rate $P$, the assurance coefficient $\varphi$ can be further obtained according to the reference table presenting the assurance coefficient of the Gumbel curve with an extreme type I distribution, which is shown in Table 3.

Table 3. Reference table of the assurance coefficient of the Gumbel curve with an extreme type I distribution.

\begin{tabular}{|c|c|c|c|c|c|c|c|c|c|c|c|c|}
\hline$P$ & 0.60 & 0.70 & 0.80 & 0.90 & 0.95 & 0.97 & 0.98 & 0.99 & 0.995 & 0.999 & 0.9995 & 0.9999 \\
\hline $\boldsymbol{\varphi}$ & 0.07 & 0.35 & 0.72 & 1.30 & 1.87 & 2.27 & 2.59 & 3.14 & 3.68 & 4.94 & 5.48 & 6.73 \\
\hline
\end{tabular}

Finally, formula (4) was adopted to calculate the basic wind speed at each station during the different reoccurrence periods. The calculated results are shown in Table 4.

$$
V_{i}=\bar{v}_{i}+\sigma_{i} \cdot \varphi
$$

\begin{tabular}{|c|c|c|c|c|c|}
\hline $\begin{array}{l}\text { Statio } \\
\text { n ID }\end{array}$ & $\begin{array}{l}\text { Valid } \\
\text { data } \\
\text { count }\end{array}$ & $\begin{array}{c}\text { Basic wind } \\
\text { speed in } 50 \\
\text { year }\end{array}$ & $\begin{array}{c}\text { Corresponding } \\
\text { wind scale in } 50 \\
\text { years }\end{array}$ & $\begin{array}{c}\text { Basic wind } \\
\text { speed in } 100 \\
\text { years }\end{array}$ & $\begin{array}{l}\text { Correspondin } \\
\mathrm{g} \text { wind scale } \\
\text { in } 100 \text { years }\end{array}$ \\
\hline 51358 & 20 & 13.77 & 6 & 14.84 & 7 \\
\hline 51367 & 23 & 13.85 & 6 & 14.89 & 7 \\
\hline 51059 & 31 & 24.87 & 10 & 26.7 & 10 \\
\hline 52112 & 12 & 23.04 & 9 & 24.2 & 9 \\
\hline 51060 & 13 & 15.15 & 7 & 16.03 & 7 \\
\hline 51720 & 12 & 14.71 & 7 & 15.98 & 7 \\
\hline 51639 & 10 & 10.41 & 5 & 11 & 6 \\
\hline 51655 & 37 & 18.33 & 8 & 19.91 & 8 \\
\hline 51704 & 39 & 20.85 & 9 & 22.62 & 9 \\
\hline 51818 & 46 & 14.33 & 7 & 15.63 & 7 \\
\hline 51730 & 12 & 12.96 & 6 & 14.02 & 7 \\
\hline
\end{tabular}

Table 4. Basic wind speed of each station in the Xinjiang Uygur Autonomous Region at different reoccurrence 


\begin{tabular}{|c|c|c|c|c|c|}
\hline 51433 & 30 & 16.14 & 7 & 17.21 & 8 \\
\hline 51526 & 32 & 15.07 & 7 & 15.92 & 7 \\
\hline 52118 & 8 & 22.59 & 9 & 23.88 & 9 \\
\hline 51633 & 12 & 15 & 7 & 16.6 & 7 \\
\hline 51701 & 16 & 21.59 & 9 & 22.84 & 9 \\
\hline 51642 & 12 & 17.7 & 8 & 19.39 & 8 \\
\hline 51365 & 12 & 14.52 & 7 & 15.69 & 7 \\
\hline 51470 & 11 & 22.97 & 9 & 24.74 & 10 \\
\hline 51656 & 46 & 22.98 & 9 & 25.03 & 10 \\
\hline 51330 & 32 & 23.99 & 9 & 26.02 & 10 \\
\hline 51238 & 32 & 12.79 & 6 & 13.78 & 6 \\
\hline 51068 & 33 & 19.33 & 8 & 20.5 & 8 \\
\hline 51053 & 32 & 22 & 9 & 23.48 & 9 \\
\hline 51542 & 45 & 22.39 & 9 & 23.49 & 9 \\
\hline 51467 & 12 & 12.86 & 6 & 13.77 & 6 \\
\hline 51186 & 30 & 12.25 & 6 & 13.13 & 6 \\
\hline 51288 & 11 & 20.5 & 8 & 21.66 & 9 \\
\hline 51810 & 25 & 15.18 & 7 & 16.53 & 7 \\
\hline 51804 & 31 & 22.88 & 9 & 24.75 & 10 \\
\hline 51765 & 12 & 12.69 & 6 & 13.38 & 6 \\
\hline 51711 & 46 & 19.22 & 8 & 20.97 & 9 \\
\hline 51839 & 46 & 14.91 & 7 & 16.01 & 7 \\
\hline 52101 & 12 & 18.48 & 8 & 19.72 & 8 \\
\hline 51243 & 46 & 31.96 & 11 & 34.46 & 12 \\
\hline 51241 & 12 & 12.75 & 6 & 13.17 & 6 \\
\hline 51232 & 46 & 35.31 & 12 & 37.34 & 12 \\
\hline 51477 & 46 & 30.57 & 11 & 32.6 & 11 \\
\hline 51931 & 46 & 13.45 & 6 & 14.59 & 7 \\
\hline 51705 & 46 & 21.62 & 9 & 22.76 & 9 \\
\hline 51087 & 32 & 19.72 & 8 & 21.3 & 9 \\
\hline 51855 & 12 & 11.73 & 6 & 12.3 & 6 \\
\hline 51437 & 46 & 20.46 & 8 & 22.14 & 9 \\
\hline 51076 & 49 & 18.18 & 8 & 19.48 & 8 \\
\hline 51156 & 12 & 25.91 & 10 & 28.41 & 10 \\
\hline 51811 & 20 & 10.69 & 5 & 11.41 & 6 \\
\hline 51628 & 46 & 19.39 & 8 & 21.37 & 9 \\
\hline 51133 & 37 & 21.17 & 9 & 22.57 & 9 \\
\hline 51346 & 32 & 10.73 & 5 & 11.32 & 6 \\
\hline 51777 & 37 & 19.98 & 8 & 21.48 & 9 \\
\hline 51828 & 49 & 14.36 & 7 & 15.59 & 7 \\
\hline 51716 & 34 & 15.55 & 7 & 16.78 & 7 \\
\hline 51334 & 32 & 17.51 & 8 & 18.77 & 8 \\
\hline 51495 & 12 & 37.15 & 12 & 38.59 & 12 \\
\hline
\end{tabular}




\begin{tabular}{|l|l|l|l|l|l|}
\hline 52313 & 12 & 19.68 & 8 & 20.58 & 8 \\
\hline 51431 & 48 & 18.72 & 8 & 20.11 & 8 \\
\hline 51573 & 46 & 19.98 & 8 & 22.15 & 9 \\
\hline 51567 & 25 & 13.73 & 6 & 14.45 & 7 \\
\hline 51379 & 32 & 23.92 & 9 & 26.42 & 10 \\
\hline 51463 & 49 & 26.8 & 10 & 29.26 & 11 \\
\hline 52203 & 47 & 19.35 & 8 & 21.03 & 9 \\
\hline 51709 & 45 & 24.4 & 9 & 26.91 & 10 \\
\hline 51644 & 46 & 17.87 & 8 & 19.47 & 8 \\
\hline 51581 & 32 & 11.72 & 6 & 12.61 & 6 \\
\hline
\end{tabular}

Due to historical reasons, only partial annual data is available for some stations, but the amount of time for which there is valid data is over 12 years for most stations. This data can reflect the realities and be used in the above calculation. Based on the results presented in Table 4, a distribution map of the basic wind speed in winter at the 50-year reoccurrence period in the Xinjiang Uygur Autonomous Region was generated, as shown in Figure 4. This analysis indicated that the wind speed was high in the west of the Changji Hui Autonomous Prefecture, the west of Turfan, the west of the Bayingolin Mongol Autonomous Prefecture, Hami, Tacheng, and the Bortala Mongol Autonomous Prefecture. The wind speed was low in Aksu, Khotan, Kashgar, and the east of the Bayingolin Mongol Autonomous Prefecture. Consequently, these results can be referred to the code of building structure design in these regions.



Figure 4. Distribution map of the basic wind speed in winter at the 50-year reoccurrence period in the Xinjiang 


\section{Snowfall distribution in winter}

In winter, precipitation is usually represented by snowfall. China has a strict regulation about the snowfall grade standard. Snowfall is the depth of an equal amount of water that originated as snow. Like rainfall, snowfall refers to the amount of snow that falls within a certain period, and this is generally measured over 24 hours. According to the standard Short-Range Weather Forecast(Centre 2017), snowfall is divided into seven grades: sporadic light snow, light snow, moderate snow, heavy snow, blizzard, storm snow, and super-big blizzard(Centre 2017). If the snowfall is much more than $10 \mathrm{~mm}$, the grade super-big blizzard can be sub-divided into two levels: big blizzard and super-big blizzard. The defined snowfall occurring at each grade within 24 hours is shown in Table 5.

As the occurrence of sporadic light snow is very small, the sporadic light snow and light snow data can be merged. Subsequently, the times of the different snowfall grades at the 64 stations in the Xinjiang Uygur Autonomous region within 1st, 2nd, 3rd, 11th, and 12th months from 1968 to 2016 were extracted. The results are shown in Table 6.

Table 5. Snowfall grade classification.

\begin{tabular}{|l|l|}
\hline Snowfall Grade & 24 hours of precipitation $(\mathrm{mm})$ \\
\hline sporadic light snow & $\leq 0.1$ \\
\hline light snow & $0.1 \sim 2.4$ \\
\hline moderate snow & $2.5 \sim 4.9$ \\
\hline heavy snow & $5.0 \sim 9.9$ \\
\hline blizzard & $10.0 \sim 19.9$ \\
\hline storm snow & $20.0 \sim 30.0$ \\
\hline super-big blizzard & $>30.0$ \\
\hline
\end{tabular}

Table 6. Occurrence times of different snowfall grades in the Xinjiang Uygur Autonomous Region within 1st, 2nd, 3rd, 11th, and 12th months from 1968 to 2016.

\begin{tabular}{|c|c|c|c|c|c|c|}
\hline $\begin{array}{r}\text { Statio } \\
\text { n ID }\end{array}$ & $\begin{array}{r}\text { Times of light } \\
\text { snow }\end{array}$ & $\begin{array}{r}\text { Times of } \\
\text { moderate snow }\end{array}$ & $\begin{array}{r}\text { Times of } \\
\text { heavy snow }\end{array}$ & $\begin{array}{l}\text { Times of } \\
\text { blizzard }\end{array}$ & $\begin{array}{l}\text { Times of } \\
\text { storm snow }\end{array}$ & $\begin{array}{r}\text { Times of super- } \\
\text { big blizzard }\end{array}$ \\
\hline 51358 & 1243 & 201 & 104 & 30 & 2 & 0 \\
\hline 51367 & 927 & 154 & 95 & 22 & 0 & 0 \\
\hline 51059 & 1391 & 230 & 105 & 16 & 0 & 0 \\
\hline 52112 & 142 & 14 & 3 & 3 & 0 & 0 \\
\hline 51060 & 1287 & 172 & 57 & 10 & 1 & 0 \\
\hline 51720 & 260 & 29 & 5 & 7 & 1 & 0 \\
\hline 51639 & 227 & 20 & 7 & 2 & 0 & 0 \\
\hline 51655 & 165 & 16 & 4 & 0 & 0 & 0 \\
\hline 51704 & 253 & 52 & 35 & 12 & 4 & 1 \\
\hline 51818 & 210 & 26 & 15 & 3 & 0 & 0 \\
\hline 51730 & 148 & 9 & 3 & 2 & 0 & 0 \\
\hline 51433 & 1084 & 327 & 195 & 61 & 4 & 0 \\
\hline 51526 & 176 & 8 & 5 & 2 & 0 & 0 \\
\hline 52118 & 360 & 25 & 7 & 2 & 1 & 0 \\
\hline 51633 & 549 & 55 & 34 & 9 & 0 & 0 \\
\hline 51701 & 1113 & 107 & 32 & 10 & 0 & 0 \\
\hline
\end{tabular}




\begin{tabular}{|c|c|c|c|c|c|c|}
\hline 51642 & 213 & 23 & 12 & 6 & 0 & 0 \\
\hline 51365 & 1074 & 150 & 57 & 4 & 0 & 0 \\
\hline 51470 & 898 & 170 & 117 & 26 & 2 & 0 \\
\hline 51656 & 242 & 19 & 5 & 2 & 1 & 0 \\
\hline 51330 & 1212 & 94 & 44 & 12 & 1 & 0 \\
\hline 51238 & 1279 & 98 & 55 & 15 & 3 & 0 \\
\hline 51068 & 1156 & 120 & 25 & 3 & 0 & 0 \\
\hline 51053 & 1354 & 219 & 90 & 27 & 2 & 0 \\
\hline 51542 & 1118 & 57 & 17 & 3 & 0 & 0 \\
\hline 51467 & 121 & 15 & 2 & 0 & 0 & 0 \\
\hline 51186 & 825 & 167 & 91 & 21 & 3 & 0 \\
\hline 51288 & 981 & 125 & 39 & 5 & 0 & 0 \\
\hline 51810 & 154 & 22 & 7 & 5 & 0 & 0 \\
\hline 51804 & 292 & 32 & 12 & 3 & 0 & 0 \\
\hline 51765 & 68 & 8 & 3 & 1 & 0 & 0 \\
\hline 51711 & 420 & 55 & 29 & 15 & 4 & 0 \\
\hline 51839 & 161 & 14 & 2 & 0 & 0 & 0 \\
\hline 52101 & 709 & 73 & 21 & 3 & 0 & 0 \\
\hline 51243 & 1107 & 62 & 17 & 3 & 0 & 0 \\
\hline 51241 & 1394 & 153 & 38 & 10 & 0 & 0 \\
\hline 51232 & 1400 & 57 & 16 & 5 & 2 & 1 \\
\hline 51477 & 336 & 14 & 1 & 0 & 0 & 0 \\
\hline 51931 & 176 & 12 & 6 & 1 & 0 & 0 \\
\hline 51705 & 566 & 70 & 42 & 10 & 4 & 0 \\
\hline 51087 & 1090 & 210 & 115 & 35 & 5 & 1 \\
\hline 51855 & 94 & 6 & 0 & 0 & 0 & 0 \\
\hline 51437 & 1165 & 183 & 74 & 9 & 1 & 0 \\
\hline 51076 & 1043 & 238 & 143 & 38 & 4 & 0 \\
\hline 51156 & 856 & 75 & 23 & 2 & 0 & 0 \\
\hline 51811 & 180 & 30 & 16 & 3 & 1 & 0 \\
\hline 51628 & 341 & 24 & 15 & 6 & 1 & 0 \\
\hline 51133 & 1193 & 344 & 181 & 70 & 10 & 2 \\
\hline 51346 & 1260 & 118 & 68 & 16 & 1 & 1 \\
\hline 51777 & 103 & 15 & 5 & 0 & 0 & 0 \\
\hline 51828 & 199 & 16 & 10 & 4 & 0 & 0 \\
\hline 51716 & 151 & 16 & 8 & 2 & 0 & 0 \\
\hline 51334 & 1465 & 58 & 29 & 4 & 0 & 0 \\
\hline 51495 & 68 & 3 & 1 & 0 & 0 & 0 \\
\hline 52313 & 347 & 12 & 4 & 1 & 0 & 0 \\
\hline 51431 & 918 & 331 & 223 & 78 & 16 & 1 \\
\hline 51573 & 96 & 9 & 4 & 3 & 0 & 0 \\
\hline 51567 & 253 & 17 & 10 & 3 & 0 & 0 \\
\hline 51379 & 971 & 159 & 68 & 5 & 0 & 0 \\
\hline
\end{tabular}




\begin{tabular}{|l|r|r|r|r|r|r|}
\hline 51463 & 1113 & 206 & 130 & 45 & 4 & 1 \\
\hline 52203 & 229 & 23 & 11 & 1 & 0 & 0 \\
\hline 51709 & 308 & 42 & 34 & 8 & 1 & 1 \\
\hline 51644 & 305 & 33 & 15 & 4 & 0 & 0 \\
\hline 51581 & 124 & 11 & 6 & 0 & 1 & 0 \\
\hline
\end{tabular}

As can be seen in Table 6, the times of high snowfall grade at stations 51433, 51133, and 51431 in the west of the Xinjiang Uygur Autonomous Region are relatively more than that of the other stations. According to the snowfall amount at each snowfall grade over 24 hours, the grades were standardized: light snow, 1; moderate snow, 2; heavy snow, 4; blizzard, 8; storm snow, 12; and super-big blizzard, 16.

As an example, at station 51431, the defined weighted cumulative snowfall grade was $918 \times 1+331 \times 2+223 \times 4+78 \times 8+16 \times 12+1 \times 16=3304$. Based on this method, the weighted accumulative snowfall grade for all of the stations in this region, as well as those nearby, was calculated, and the distribution map of the weighted cumulative snowfall grade in the Xinjiang Uygur Autonomous region was generated, as shown in Figure 5.

\section{Distribution map of weighted accumulative snowfall grade in the Xinjiang Uygur Autonomous Region}

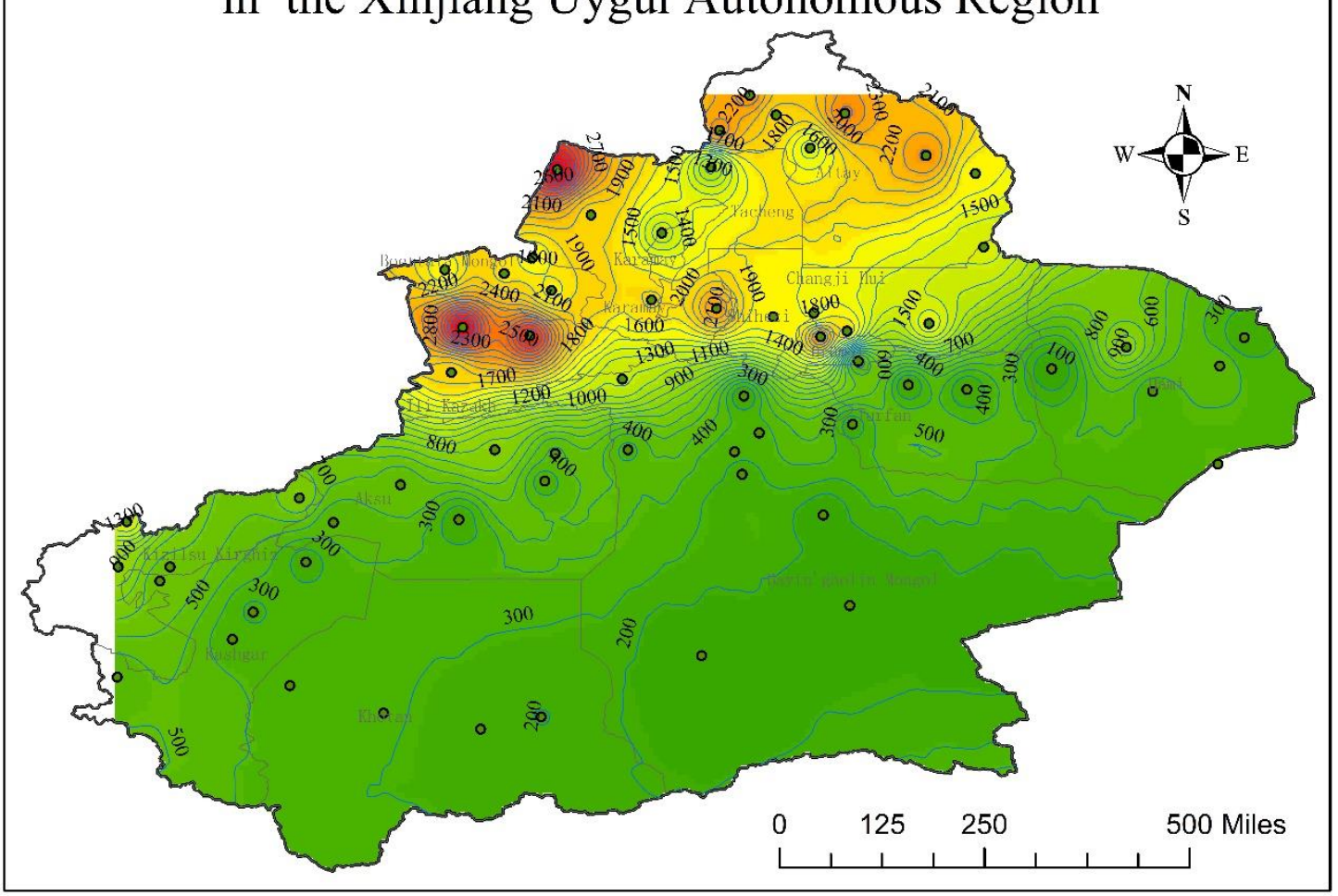

Figure 5. Distribution map of weighted accumulative snowfall grade in the Xinjiang Uygur Autonomous region.

According to Figure 5, we know that the snowfall areas of the Xinjiang Uygur Autonomous Region are mainly in the north, and the heaviest snowfalls are in the Yili Kazak Autonomous and the northwestern Tacheng Prefectures. The snowfall is medium in Altay, the Changji Hui Autonomous Prefecture, Shihezi City, Urumqi, and the Tacheng Prefectures except for the northwest. 


\section{Accumulative snowfall and wind scale for the top ten maximum snowfall days}

230

231

\section{in winter}

As most snow drift disasters occur after a heavy snowfall, the authors extracted the wind scales of six days (including the day of the snowfall) after the top ten maximum snowfall days in winter in the Xinjiang Uygur Autonomous Region by using the above data, and then the wind grades on these 60 days are classified. The numbers of occurrences of different wind scales at all stations during these 60 days are shown in Table 7. In this data of 60 days at all stations, one day's data at stations 51431 and 51470 and two days' data at stations 51433 and 51704 are missing. To analyze the wind power during these 60 days, the authors multiplied the different wind scales and their corresponding appearance frequency for each station, and then calculated the accumulation. Based on this method, the cumulative wind scale distribution map can be obtained if the contemporaneous data from the nearby regional sites are added during the calculation process. The distribution map is shown in Figure 6. For the missing data at different stations, we used the average value on the other days.

Table 7. The numbers of occurrences of different wind scales for six days (including the day of snowfall) after the top ten maximum snowfall days in winter at all stations in the Xinjiang Uygur Autonomous Region.

\begin{tabular}{|c|c|c|c|c|c|c|c|c|c|c|c|}
\hline $\begin{array}{l}\text { Station } \\
\text { ID }\end{array}$ & $\begin{array}{l}\text { Times } \\
\text { of Wind } \\
\text { scale } 0\end{array}$ & $\begin{array}{l}\text { Times } \\
\text { of Wind } \\
\text { scale } 1\end{array}$ & $\begin{array}{l}\text { Times } \\
\text { of Wind } \\
\text { scale } 2\end{array}$ & $\begin{array}{l}\text { Times } \\
\text { of Wind } \\
\text { scale } 3\end{array}$ & $\begin{array}{l}\text { Times } \\
\text { of Wind } \\
\text { scale } 4\end{array}$ & $\begin{array}{l}\text { Times } \\
\text { of Wind } \\
\text { scale } 5\end{array}$ & $\begin{array}{l}\text { Times } \\
\text { of Wind } \\
\text { scale } 6\end{array}$ & $\begin{array}{l}\text { Times } \\
\text { of } \\
\text { Wind } \\
\text { scale } 7\end{array}$ & $\begin{array}{l}\text { Times } \\
\text { of } \\
\text { Wind } \\
\text { scale } 8\end{array}$ & $\begin{array}{l}\text { Count } \\
\text { of } \\
\text { missin } \\
\text { g data }\end{array}$ & $\begin{array}{l}\text { Accu } \\
\text { mulati } \\
\text { ve } \\
\text { wind } \\
\text { scale }\end{array}$ \\
\hline 51053 & 0 & 6 & 18 & 19 & 17 & 0 & 0 & 0 & 0 & 0 & 167 \\
\hline 51059 & 0 & 24 & 16 & 12 & 5 & 1 & 2 & 0 & 0 & 0 & 129 \\
\hline 51060 & 0 & 4 & 23 & 27 & 5 & 1 & 0 & 0 & 0 & 0 & 156 \\
\hline 51068 & 0 & 14 & 35 & 9 & 2 & 0 & 0 & 0 & 0 & 0 & 119 \\
\hline 51076 & 3 & 33 & 20 & 3 & 1 & 0 & 0 & 0 & 0 & 0 & 86 \\
\hline 51087 & 13 & 32 & 10 & 5 & 0 & 0 & 0 & 0 & 0 & 0 & 67 \\
\hline 51133 & 1 & 29 & 21 & 8 & 1 & 0 & 0 & 0 & 0 & 0 & 99 \\
\hline 51156 & 6 & 19 & 25 & 7 & 3 & 0 & 0 & 0 & 0 & 0 & 102 \\
\hline 51186 & 18 & 36 & 6 & 0 & 0 & 0 & 0 & 0 & 0 & 0 & 48 \\
\hline 51232 & 0 & 6 & 18 & 20 & 6 & 0 & 4 & 2 & 4 & 0 & 196 \\
\hline 51238 & 0 & 31 & 28 & 1 & 0 & 0 & 0 & 0 & 0 & 0 & 90 \\
\hline 51241 & 1 & 24 & 32 & 3 & 0 & 0 & 0 & 0 & 0 & 0 & 97 \\
\hline 51243 & 8 & 21 & 20 & 7 & 4 & 0 & 0 & 0 & 0 & 0 & 98 \\
\hline 51288 & 2 & 15 & 33 & 6 & 3 & 1 & 0 & 0 & 0 & 0 & 116 \\
\hline 51330 & 3 & 38 & 19 & 0 & 0 & 0 & 0 & 0 & 0 & 0 & 76 \\
\hline 51334 & 4 & 38 & 15 & 3 & 0 & 0 & 0 & 0 & 0 & 0 & 77 \\
\hline 51346 & 1 & 29 & 28 & 2 & 0 & 0 & 0 & 0 & 0 & 0 & 91 \\
\hline 51358 & 11 & 34 & 15 & 0 & 0 & 0 & 0 & 0 & 0 & 0 & 64 \\
\hline 51365 & 1 & 27 & 30 & 2 & 0 & 0 & 0 & 0 & 0 & 0 & 93 \\
\hline 51367 & 0 & 19 & 40 & 1 & 0 & 0 & 0 & 0 & 0 & 0 & 102 \\
\hline 51379 & 0 & 5 & 46 & 8 & 1 & 0 & 0 & 0 & 0 & 0 & 125 \\
\hline
\end{tabular}




\begin{tabular}{|c|c|c|c|c|c|c|c|c|c|c|c|}
\hline 51431 & 0 & 28 & 28 & 3 & 0 & 0 & 0 & 0 & 0 & 1 & 94.4 \\
\hline 51433 & 8 & 35 & 9 & 5 & 1 & 0 & 0 & 0 & 0 & 2 & 73.6 \\
\hline 51437 & 0 & 30 & 27 & 3 & 0 & 0 & 0 & 0 & 0 & 0 & 93 \\
\hline 51463 & 0 & 21 & 36 & 3 & 0 & 0 & 0 & 0 & 0 & 0 & 102 \\
\hline 51467 & 5 & 23 & 30 & 2 & 0 & 0 & 0 & 0 & 0 & 0 & 89 \\
\hline 51470 & 0 & 1 & 36 & 21 & 1 & 0 & 0 & 0 & 0 & 1 & 142 \\
\hline 51477 & 0 & 4 & 18 & 12 & 13 & 9 & 4 & 0 & 0 & 0 & 197 \\
\hline 51495 & 2 & 11 & 17 & 13 & 2 & 9 & 2 & 3 & 1 & 0 & 178 \\
\hline 51526 & 0 & 34 & 26 & 0 & 0 & 0 & 0 & 0 & 0 & 0 & 86 \\
\hline 51542 & 0 & 27 & 30 & 3 & 0 & 0 & 0 & 0 & 0 & 0 & 96 \\
\hline 51567 & 5 & 35 & 16 & 4 & 0 & 0 & 0 & 0 & 0 & 0 & 79 \\
\hline 51573 & 11 & 42 & 7 & 0 & 0 & 0 & 0 & 0 & 0 & 0 & 56 \\
\hline 51581 & 2 & 48 & 10 & 0 & 0 & 0 & 0 & 0 & 0 & 0 & 68 \\
\hline 51628 & 0 & 42 & 18 & 0 & 0 & 0 & 0 & 0 & 0 & 0 & 78 \\
\hline 51633 & 5 & 48 & 6 & 1 & 0 & 0 & 0 & 0 & 0 & 0 & 63 \\
\hline 51639 & 5 & 35 & 20 & 0 & 0 & 0 & 0 & 0 & 0 & 0 & 75 \\
\hline 51642 & 12 & 30 & 18 & 0 & 0 & 0 & 0 & 0 & 0 & 0 & 66 \\
\hline 51644 & 0 & 30 & 29 & 1 & 0 & 0 & 0 & 0 & 0 & 0 & 91 \\
\hline 51655 & 3 & 46 & 9 & 2 & 0 & 0 & 0 & 0 & 0 & 0 & 70 \\
\hline 51656 & 1 & 30 & 25 & 2 & 2 & 0 & 0 & 0 & 0 & 0 & 94 \\
\hline 51701 & 0 & 7 & 33 & 15 & 3 & 2 & 0 & 0 & 0 & 0 & 140 \\
\hline 51704 & 4 & 43 & 11 & 0 & 0 & 0 & 0 & 0 & 0 & 2 & 67.5 \\
\hline 51705 & 3 & 35 & 15 & 3 & 1 & 3 & 0 & 0 & 0 & 0 & 93 \\
\hline 51709 & 0 & 36 & 24 & 0 & 0 & 0 & 0 & 0 & 0 & 0 & 84 \\
\hline 51711 & 0 & 12 & 33 & 14 & 1 & 0 & 0 & 0 & 0 & 0 & 124 \\
\hline 51716 & 1 & 36 & 21 & 2 & 0 & 0 & 0 & 0 & 0 & 0 & 84 \\
\hline 51720 & 6 & 37 & 17 & 0 & 0 & 0 & 0 & 0 & 0 & 0 & 71 \\
\hline 51730 & 1 & 44 & 14 & 1 & 0 & 0 & 0 & 0 & 0 & 0 & 75 \\
\hline 51765 & 0 & 30 & 26 & 4 & 0 & 0 & 0 & 0 & 0 & 0 & 94 \\
\hline 51777 & 1 & 20 & 27 & 7 & 5 & 0 & 0 & 0 & 0 & 0 & 115 \\
\hline 51804 & 12 & 35 & 11 & 2 & 0 & 0 & 0 & 0 & 0 & 0 & 63 \\
\hline 51810 & 8 & 41 & 10 & 1 & 0 & 0 & 0 & 0 & 0 & 0 & 64 \\
\hline 51811 & 1 & 38 & 16 & 3 & 2 & 0 & 0 & 0 & 0 & 0 & 87 \\
\hline 51818 & 0 & 26 & 27 & 4 & 3 & 0 & 0 & 0 & 0 & 0 & 104 \\
\hline 51828 & 0 & 23 & 34 & 3 & 0 & 0 & 0 & 0 & 0 & 0 & 100 \\
\hline 51839 & 6 & 35 & 18 & 1 & 0 & 0 & 0 & 0 & 0 & 0 & 74 \\
\hline 51855 & 5 & 36 & 15 & 4 & 0 & 0 & 0 & 0 & 0 & 0 & 78 \\
\hline 51931 & 2 & 45 & 12 & 1 & 0 & 0 & 0 & 0 & 0 & 0 & 72 \\
\hline 52101 & 2 & 18 & 29 & 8 & 3 & 0 & 0 & 0 & 0 & 0 & 112 \\
\hline 52112 & 1 & 12 & 27 & 12 & 8 & 0 & 0 & 0 & 0 & 0 & 134 \\
\hline 52118 & 3 & 10 & 20 & 20 & 7 & 0 & 0 & 0 & 0 & 0 & 138 \\
\hline 52203 & 1 & 41 & 17 & 1 & 0 & 0 & 0 & 0 & 0 & 0 & 78 \\
\hline 52313 & 0 & 2 & 28 & 24 & 5 & 1 & 0 & 0 & 0 & 0 & 155 \\
\hline
\end{tabular}


Distribution map of the accumulative wind scale from the top ten maximum snowfall days at all stations in the Xinjiang Uygur Autonomous Region

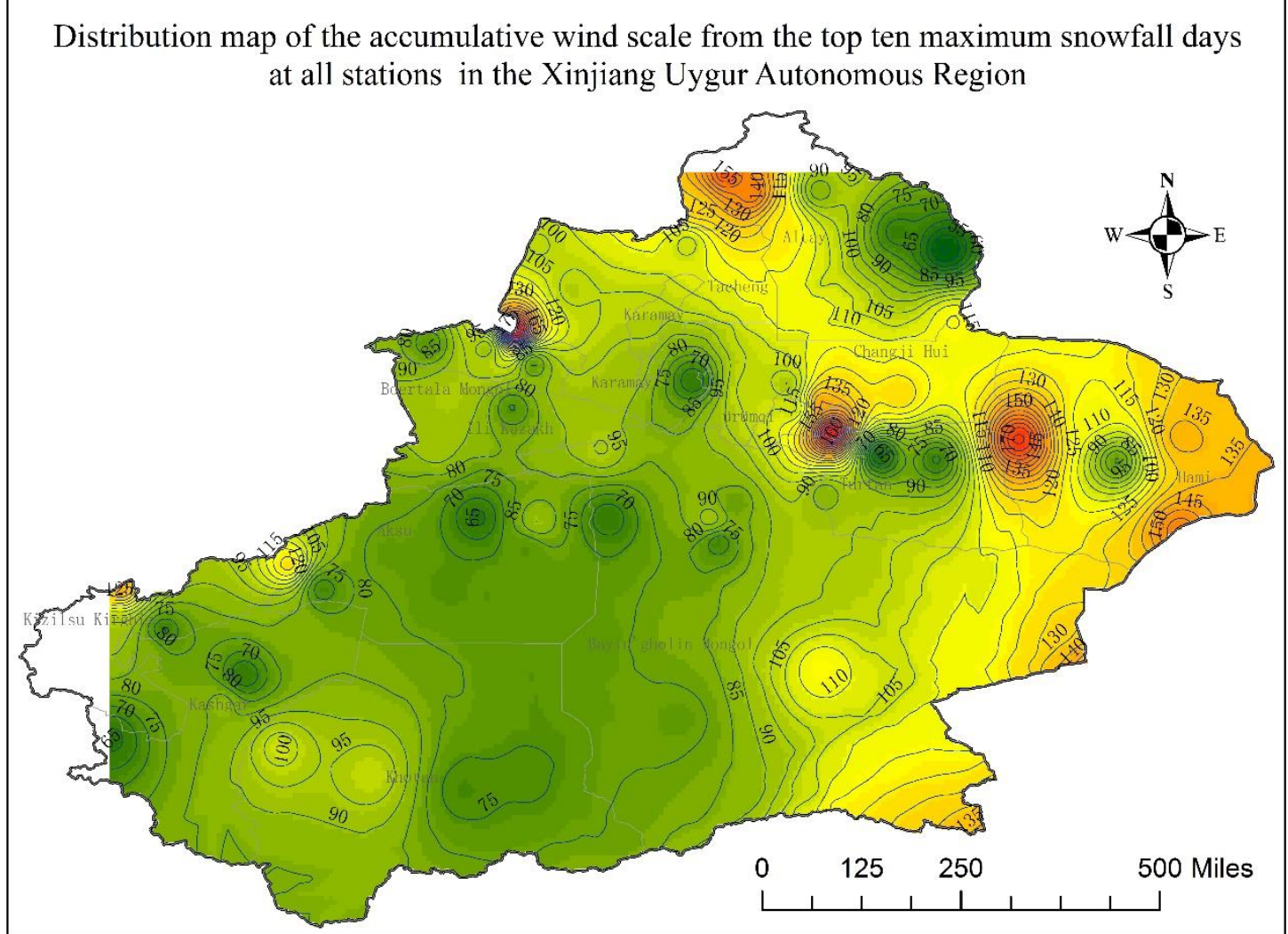

Figure 6. Distribution map of the accumulative wind scale from the top ten maximum snowfall days at all stations in the Xinjiang Uygur Autonomous Region.

From Figure 6, we can know that the wind is very strong in northern Altay, western Hami city, western Urumqi, and at the junction of the Bortala Mongol Autonomous and Tacheng Prefectures after heavy snowfalls. The wind in eastern Hami city and the northern Kizilsukirgiz Autonomous Prefecture is weaker than the above areas. While in the other areas, the wind is weakest.

The above is the analysis of the cumulative wind scale for six days (including the day of snowfall) after the top ten maximum snowfall days in winter at all stations in the Xinjiang Uygur Autonomous Region, without considering the total snowfall on the top ten maximum snowfall days. Therefore, the authors analyzed the joint distribution of the total snowfall on the top ten maximum snowfall days and the accumulated wind scale on six days (including the day of the snowfall) after the top ten maximum snowfall days. First, the authors calculated the total snowfall for the top ten maximum snowfall days, and then calculated the cumulative wind scale for six days (including the day of snowfall) after the top ten maximum snowfall days. In order to compare the joint distribution of the total snowfall and the accumulated wind scale, these data are normalized according to Formulas 1 and 2. After these calculations, the total snowfall, the accumulated wind scale, average wind scale, normalized total snowfall, and normalized accumulated wind scale are shown in Table 8.

$$
\text { Wind }^{*}=\frac{\text { Wind }}{\text { Wind }_{\max }}
$$

$$
\text { Snow }^{*}=\frac{\text { Snow }}{\text { Snow }_{\max }}
$$


of the Xinjiang Uygur Autonomous Region, which is shown in Figure 7.

267 Table 8. The normalized total snowfall and the normalized accumulated wind scale of all stations in the Xinjiang

Uygur Autonomous Region.

\begin{tabular}{|c|c|c|c|c|c|}
\hline Station ID & $\begin{array}{l}\text { Accumulative } \\
\text { amount of } \\
\text { snowfall (mm) }\end{array}$ & $\begin{array}{l}\text { Accumulative } \\
\text { wind scale }\end{array}$ & $\begin{array}{l}\text { Average daily } \\
\text { wind scale }\end{array}$ & $\begin{array}{l}\text { Normalized } \\
\text { accumulative } \\
\text { snowfall }\end{array}$ & $\begin{array}{l}\text { Normalized } \\
\text { accumulative wind } \\
\text { scale }\end{array}$ \\
\hline 51053 & 181.8 & 167.000 & 2.783 & 0.697 & 0.848 \\
\hline 51059 & 131.8 & 129.000 & 2.150 & 0.505 & 0.655 \\
\hline 51060 & 135.8 & 156.000 & 2.600 & 0.521 & 0.792 \\
\hline 51068 & 91.4 & 119.000 & 1.983 & 0.350 & 0.604 \\
\hline 51076 & 189.6 & 86.000 & 1.433 & 0.727 & 0.437 \\
\hline 51087 & 224.6 & 67.000 & 1.117 & 0.861 & 0.340 \\
\hline 51133 & 255.6 & 99.000 & 1.650 & 0.980 & 0.503 \\
\hline 51156 & 84.1 & 102.000 & 1.700 & 0.322 & 0.518 \\
\hline 51186 & 193.5 & 48.000 & 0.800 & 0.742 & 0.244 \\
\hline 51232 & 170.4 & 196.000 & 3.267 & 0.653 & 0.995 \\
\hline 51238 & 180.3 & 90.000 & 1.500 & 0.691 & 0.457 \\
\hline 51241 & 129 & 97.000 & 1.617 & 0.495 & 0.492 \\
\hline 51243 & 90.4 & 98.000 & 1.633 & 0.347 & 0.497 \\
\hline 51288 & 110.8 & 116.000 & 1.933 & 0.425 & 0.589 \\
\hline 51330 & 145 & 76.000 & 1.267 & 0.556 & 0.386 \\
\hline 51334 & 99.9 & 77.000 & 1.283 & 0.383 & 0.391 \\
\hline 51346 & 175.2 & 91.000 & 1.517 & 0.672 & 0.462 \\
\hline 51358 & 182.5 & 64.000 & 1.067 & 0.700 & 0.325 \\
\hline 51365 & 106.3 & 93.000 & 1.550 & 0.408 & 0.472 \\
\hline 51367 & 128.6 & 102.000 & 1.700 & 0.493 & 0.518 \\
\hline 51379 & 112.2 & 125.000 & 2.083 & 0.430 & 0.635 \\
\hline 51431 & 260.8 & 94.576 & 1.576 & 1.000 & 0.480 \\
\hline 51433 & 198.6 & 74.483 & 1.241 & 0.762 & 0.378 \\
\hline 51437 & 130.8 & 93.000 & 1.550 & 0.502 & 0.472 \\
\hline 51463 & 214.6 & 102.000 & 1.700 & 0.823 & 0.518 \\
\hline 51467 & 42.2 & 89.000 & 1.483 & 0.162 & 0.452 \\
\hline 51470 & 177.5 & 142.373 & 2.373 & 0.681 & 0.723 \\
\hline 51477 & 41.3 & 197.000 & 3.283 & 0.158 & 1.000 \\
\hline 51495 & 25.4 & 178.000 & 2.967 & 0.097 & 0.904 \\
\hline 51526 & 63.2 & 86.000 & 1.433 & 0.242 & 0.437 \\
\hline 51542 & 97 & 96.000 & 1.600 & 0.372 & 0.487 \\
\hline 51567 & 94.3 & 79.000 & 1.317 & 0.362 & 0.401 \\
\hline 51573 & 71.4 & 56.000 & 0.933 & 0.274 & 0.284 \\
\hline 51581 & 72.2 & 68.000 & 1.133 & 0.277 & 0.345 \\
\hline 51628 & 125.3 & 78.000 & 1.300 & 0.480 & 0.396 \\
\hline 51633 & 126.5 & 63.000 & 1.050 & 0.485 & 0.320 \\
\hline 51639 & 80.8 & 75.000 & 1.250 & 0.310 & 0.381 \\
\hline
\end{tabular}




\begin{tabular}{|c|c|c|c|c|c|}
\hline 51642 & 106.9 & 66.000 & 1.100 & 0.410 & 0.335 \\
\hline 51644 & 99 & 91.000 & 1.517 & 0.380 & 0.462 \\
\hline 51655 & 50.6 & 70.000 & 1.167 & 0.194 & 0.355 \\
\hline 51656 & 88.4 & 94.000 & 1.567 & 0.339 & 0.477 \\
\hline 51701 & 141.6 & 140.000 & 2.333 & 0.543 & 0.711 \\
\hline 51704 & 232.9 & 67.241 & 1.121 & 0.893 & 0.341 \\
\hline 51705 & 179.2 & 93.000 & 1.550 & 0.687 & 0.472 \\
\hline 51709 & 174.7 & 84.000 & 1.400 & 0.670 & 0.426 \\
\hline 51711 & 184.8 & 124.000 & 2.067 & 0.709 & 0.629 \\
\hline 51716 & 79.2 & 84.000 & 1.400 & 0.304 & 0.426 \\
\hline 51720 & 122.8 & 71.000 & 1.183 & 0.471 & 0.360 \\
\hline 51730 & 61.3 & 75.000 & 1.250 & 0.235 & 0.381 \\
\hline 51765 & 53.3 & 94.000 & 1.567 & 0.204 & 0.477 \\
\hline 51777 & 53.1 & 115.000 & 1.917 & 0.204 & 0.584 \\
\hline 51804 & 88.8 & 63.000 & 1.050 & 0.340 & 0.320 \\
\hline 51810 & 102.3 & 64.000 & 1.067 & 0.392 & 0.325 \\
\hline 51811 & 123.2 & 87.000 & 1.450 & 0.472 & 0.442 \\
\hline 51818 & 91.8 & 104.000 & 1.733 & 0.352 & 0.528 \\
\hline 51828 & 97.9 & 100.000 & 1.667 & 0.375 & 0.508 \\
\hline 51839 & 48.5 & 74.000 & 1.233 & 0.186 & 0.376 \\
\hline 51855 & 33.4 & 78.000 & 1.300 & 0.128 & 0.396 \\
\hline 51931 & 70.9 & 72.000 & 1.200 & 0.272 & 0.365 \\
\hline 52101 & 85.5 & 112.000 & 1.867 & 0.328 & 0.569 \\
\hline 52112 & 83.9 & 134.000 & 2.233 & 0.322 & 0.680 \\
\hline 52118 & 107.2 & 138.000 & 2.300 & 0.411 & 0.701 \\
\hline 52203 & 79.7 & 78.000 & 1.300 & 0.306 & 0.396 \\
\hline 52313 & 59 & 155.000 & 2.583 & 0.226 & 0.787 \\
\hline
\end{tabular}


Joint distribution map of the total snowfall for the top ten maximum snowfall days and the accumulative wind scale for six days (including the day of snowfall) after the top ten maximum snowfall day at all stations in the Xinjiang Uygur Autonomous Region

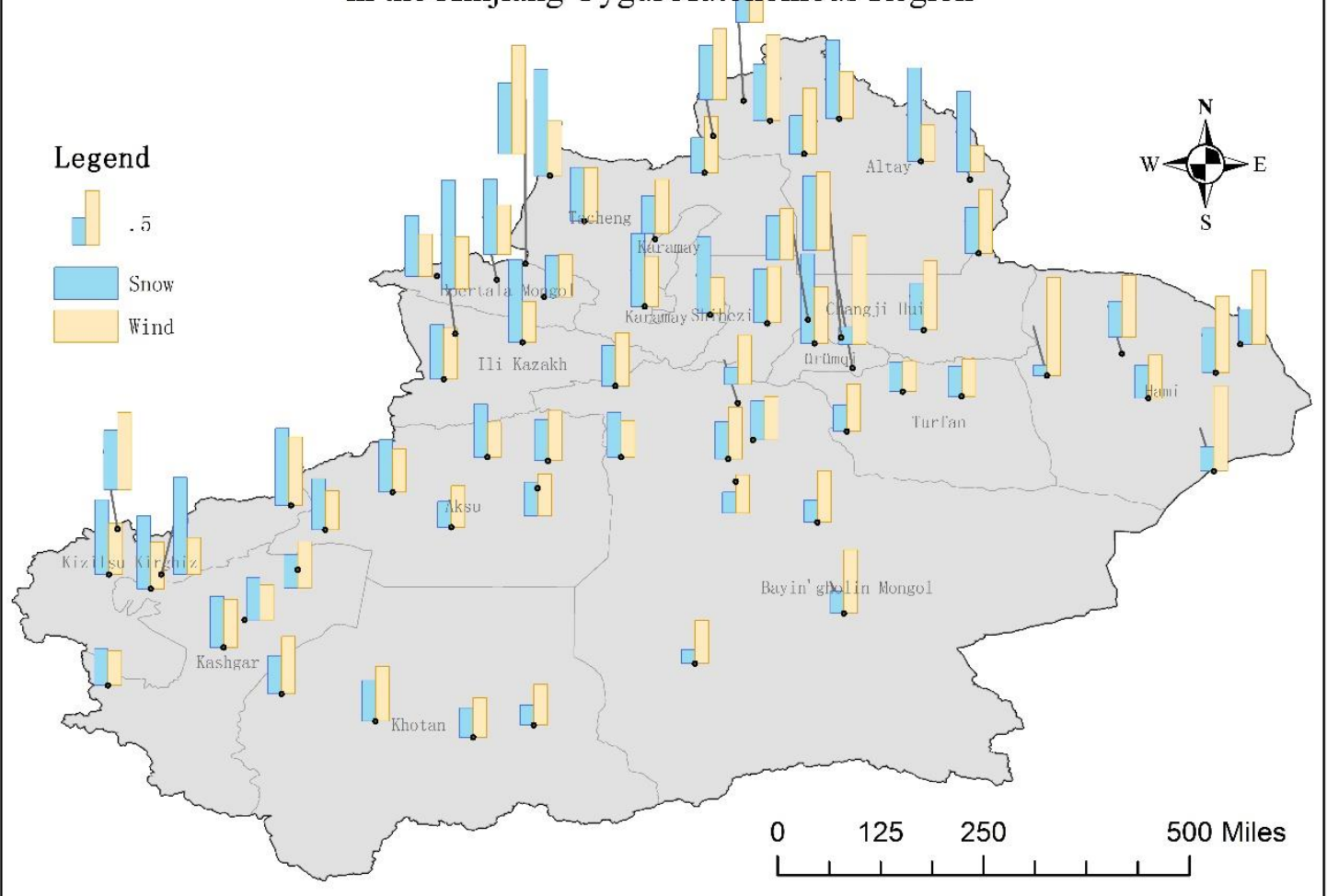

Figure 7. Joint distribution map of the total snowfall for the top ten maximum snowfall days and the accumulative wind scale for six days (including the day of snowfall) after the top ten maximum snowfall day at all stations in the Xinjiang Uygur Autonomous Region.

From Figure 7, we can draw four conclusions. (1) After heavy snowfalls, the wind is very strong in the northwestern Altay, the northwestern Tacheng Prefecture and Urumqi city. So, the snowdrift disasters that occur in these areas are very serious. (2) After a heavy snowfall, the wind is not very strong in the Kizilsu Kirghiz Autonomous Prefecture, the Bortala Mongol Autonomous Prefecture and northeastern Altay. So, the snowdrift disasters in these areas are not serious. (3) After a snowfall, the wind is very strong, but it does not snow very much in Hami city. So, it has potential to become an area with serious snowdrift disasters. (4) After snowfalls, the wind is very weak, and the snowfall is less than it is in other areas. So, the probability of the occurrence of snowdrift disasters is much lower than in the other areas.

\section{Cumulative snowfall and wind scale in relation to the top ten maximum snowfall}

\section{events in winter}

In section 5, the authors analyzed the cumulative wind scale for the top ten maximum snowfall day at all stations in the Xinjiang Uygur Autonomous Region, without considering the total snowfall of the top ten maximum snowfall events in winter. Therefore, the authors extracted the wind scales of the days on which the top ten maximum snowfall events happened, and the wind scales of the five days after these snowfall events in winter in the Xinjiang Uygur Autonomous Region by using the above data. In this data on the different days at all stations, one day's data at stations 51431, 51470, 51431, 51346 and 51704, and two days' data at stations 51433 is missing. For the missing 
data at different stations, we used the average value of the last days. To compare the joint distribution of the total snowfall and the accumulated wind scale, these data are also normalized according to the Formulas 1 and 2. After these processes, the average wind scale, maximum wind scale, normalized total snowfall, and normalized accumulated wind scale are shown in Table 9.

Table 9. Accumulative snowfall and accumulative wind scale taken from the top ten maximum snowfall events at each station in the Xinjiang Uygur Autonomous Region.

\begin{tabular}{|c|c|c|c|c|c|c|c|}
\hline $\begin{array}{l}\text { Station } \\
\text { ID }\end{array}$ & $\begin{array}{l}\text { Total } \\
\text { snowing } \\
\text { days (d) }\end{array}$ & $\begin{array}{l}\text { Accumulative } \\
\text { amount of } \\
\text { snowfall (mm) }\end{array}$ & $\begin{array}{l}\text { Accumula } \\
\text { tive wind } \\
\text { scale }\end{array}$ & $\begin{array}{l}\text { Average } \\
\text { daily wind } \\
\text { scale }\end{array}$ & $\begin{array}{l}\text { Maximu } \\
\text { m wind } \\
\text { scale }\end{array}$ & $\begin{array}{l}\text { Normalized } \\
\text { accumulative } \\
\text { snowfall }\end{array}$ & $\begin{array}{l}\text { Normalized } \\
\text { accumulative } \\
\text { wind scale }\end{array}$ \\
\hline 51053 & 46 & 256.1 & 283 & 2.948 & 6 & 0.519 & 0.990 \\
\hline 51059 & 48 & 242.3 & 212 & 2.163 & 6 & 0.491 & 0.741 \\
\hline 51060 & 45 & 212.8 & 256 & 2.695 & 5 & 0.431 & 0.895 \\
\hline 51068 & 39 & 114.1 & 162 & 1.820 & 4 & 0.231 & 0.566 \\
\hline 51076 & 59 & 301.8 & 151 & 1.385 & 3 & 0.612 & 0.528 \\
\hline 51087 & 56 & 365.8 & 118 & 1.113 & 3 & 0.741 & 0.413 \\
\hline 51133 & 45 & 426.8 & 137 & 1.442 & 3 & 0.865 & 0.479 \\
\hline 51156 & 31 & 114.2 & 130 & 1.605 & 4 & 0.231 & 0.455 \\
\hline 51186 & 46 & 304.9 & 84 & 0.875 & 2 & 0.618 & 0.294 \\
\hline 51232 & 51 & 116.9 & 286 & 2.832 & 8 & 0.237 & 1.000 \\
\hline 51238 & 28 & 204.2 & 98 & 1.256 & 2 & 0.414 & 0.343 \\
\hline 51241 & 51 & 171 & 183 & 1.812 & 3 & 0.347 & 0.640 \\
\hline 51243 & 33 & 111.4 & 131 & 1.578 & 5 & 0.226 & 0.458 \\
\hline 51288 & 38 & 146.4 & 188 & 2.136 & 5 & 0.297 & 0.657 \\
\hline 51330 & 43 & 166.1 & 123 & 1.323 & 5 & 0.337 & 0.430 \\
\hline 51334 & 48 & 118.2 & 99 & 1.010 & 3 & 0.240 & 0.346 \\
\hline 51346 & 29 & 222 & 116.08 & 1.469 & 3 & 0.450 & 0.406 \\
\hline 51358 & 49 & 257.8 & 112 & 1.131 & 2 & 0.522 & 0.392 \\
\hline 51365 & 24 & 125.8 & 120 & 1.622 & 3 & 0.255 & 0.420 \\
\hline 51367 & 38 & 173.7 & 155 & 1.761 & 3 & 0.352 & 0.542 \\
\hline 51379 & 29 & 138.2 & 157 & 1.987 & 3 & 0.280 & 0.549 \\
\hline 51431 & 53 & 493.5 & 143.22 & 1.390 & 3 & 1.000 & 0.501 \\
\hline 51433 & 53 & 426.6 & 134.82 & 1.309 & 5 & 0.864 & 0.471 \\
\hline 51437 & 46 & 181.3 & 142 & 1.479 & 3 & 0.367 & 0.497 \\
\hline 51463 & 33 & 263.5 & 133 & 1.602 & 3 & 0.534 & 0.465 \\
\hline 51467 & 17 & 51.2 & 102 & 1.522 & 3 & 0.104 & 0.357 \\
\hline 51470 & 37 & 245.4 & 197 & 2.264 & 4 & 0.497 & 0.689 \\
\hline 51477 & 24 & 53.7 & 239 & 3.230 & 6 & 0.109 & 0.836 \\
\hline 51495 & 17 & 21.9 & 160 & 2.388 & 8 & 0.044 & 0.559 \\
\hline 51526 & 16 & 63.4 & 100 & 1.515 & 4 & 0.128 & 0.350 \\
\hline 51542 & 44 & 85.9 & 172 & 1.830 & 5 & 0.174 & 0.601 \\
\hline 51567 & 23 & 91.8 & 96 & 1.315 & 3 & 0.186 & 0.336 \\
\hline 51573 & 13 & 72.1 & 66 & 1.048 & 2 & 0.146 & 0.231 \\
\hline 51581 & 17 & 81.4 & 79 & 1.179 & 2 & 0.165 & 0.276 \\
\hline
\end{tabular}




\begin{tabular}{|c|c|c|c|c|c|c|c|}
\hline 51628 & 30 & 177.2 & 114 & 1.425 & 3 & 0.359 & 0.399 \\
\hline 51633 & 41 & 170.2 & 86 & 0.945 & 3 & 0.345 & 0.301 \\
\hline 51639 & 29 & 100.9 & 93 & 1.177 & 2 & 0.204 & 0.325 \\
\hline 51642 & 20 & 127.1 & 85 & 1.214 & 2 & 0.258 & 0.297 \\
\hline 51644 & 31 & 117.1 & 124 & 1.531 & 2 & 0.237 & 0.434 \\
\hline 51655 & 15 & 58.9 & 75 & 1.154 & 3 & 0.119 & 0.262 \\
\hline 51656 & 26 & 76.1 & 110 & 1.447 & 4 & 0.154 & 0.385 \\
\hline 51701 & 61 & 245.5 & 255 & 2.297 & 5 & 0.497 & 0.892 \\
\hline 51704 & 28 & 249.1 & 97.13 & 1.245 & 3 & 0.505 & 0.340 \\
\hline 51705 & 32 & 193 & 123 & 1.500 & 5 & 0.391 & 0.430 \\
\hline 51709 & 30 & 201.9 & 108 & 1.350 & 2 & 0.409 & 0.378 \\
\hline 51711 & 29 & 182 & 147 & 1.861 & 3 & 0.369 & 0.514 \\
\hline 51716 & 18 & 72.8 & 87 & 1.279 & 3 & 0.148 & 0.304 \\
\hline 51720 & 32 & 130.6 & 102 & 1.244 & 3 & 0.265 & 0.357 \\
\hline 51730 & 24 & 60 & 82 & 1.108 & 2 & 0.122 & 0.287 \\
\hline 51765 & 12 & 42.9 & 96 & 1.548 & 3 & 0.087 & 0.336 \\
\hline 51777 & 21 & 64.7 & 128 & 1.803 & 4 & 0.131 & 0.448 \\
\hline 51804 & 28 & 103.8 & 73 & 0.936 & 2 & 0.210 & 0.255 \\
\hline 51810 & 29 & 100.6 & 89 & 1.127 & 2 & 0.204 & 0.311 \\
\hline 51811 & 29 & 144.7 & 98 & 1.241 & 3 & 0.293 & 0.343 \\
\hline 51818 & 32 & 130.9 & 115 & 1.402 & 3 & 0.265 & 0.402 \\
\hline 51828 & 29 & 114.3 & 131 & 1.658 & 4 & 0.232 & 0.458 \\
\hline 51839 & 31 & 50.3 & 93 & 1.148 & 3 & 0.102 & 0.325 \\
\hline 51855 & 20 & 40.1 & 87 & 1.243 & 3 & 0.081 & 0.304 \\
\hline 51931 & 29 & 72.3 & 89 & 1.127 & 2 & 0.147 & 0.311 \\
\hline 52101 & 25 & 83.9 & 141 & 1.880 & 5 & 0.170 & 0.493 \\
\hline 52112 & 25 & 93.4 & 152 & 2.027 & 4 & 0.189 & 0.531 \\
\hline 52118 & 23 & 73.3 & 169 & 2.315 & 5 & 0.149 & 0.591 \\
\hline 52203 & 20 & 97.4 & 90 & 1.286 & 3 & 0.197 & 0.315 \\
\hline 52313 & 20 & 65.9 & 190 & 2.714 & 5 & 0.134 & 0.664 \\
\hline
\end{tabular}

Based on the above normalized snowfall and wind scale data, a joint distribution map of the accumulative snowfall and wind scales at each station in the Xinjiang Uygur Autonomous Region was generated (Figure 8). It can be seen from this map that, after the top ten heavy snowfall events, the accumulative wind scale is high and the cumulative snowfall is large in the Altay Prefecture, the Bortala Mongol Autonomous Prefecture, the Tacheng Prefecture of the northern Xinjiang, and the Kizilsu Kirghiz Autonomous Prefecture of the western Xinjiang. However, in regard to the Altay Prefecture, the accumulative wind scale is higher in its northwestern quadrant than its southeastern counterpart. The cumulative wind scale is high, but the accumulative snowfall is small in the Hami Prefecture. In other areas, both are small. 
Joint distribution map of the accumulative snowfall and accumulative wind scale from the top ten maximum snowfall events at each station in the Xinjiang Uygur Autonomous Region

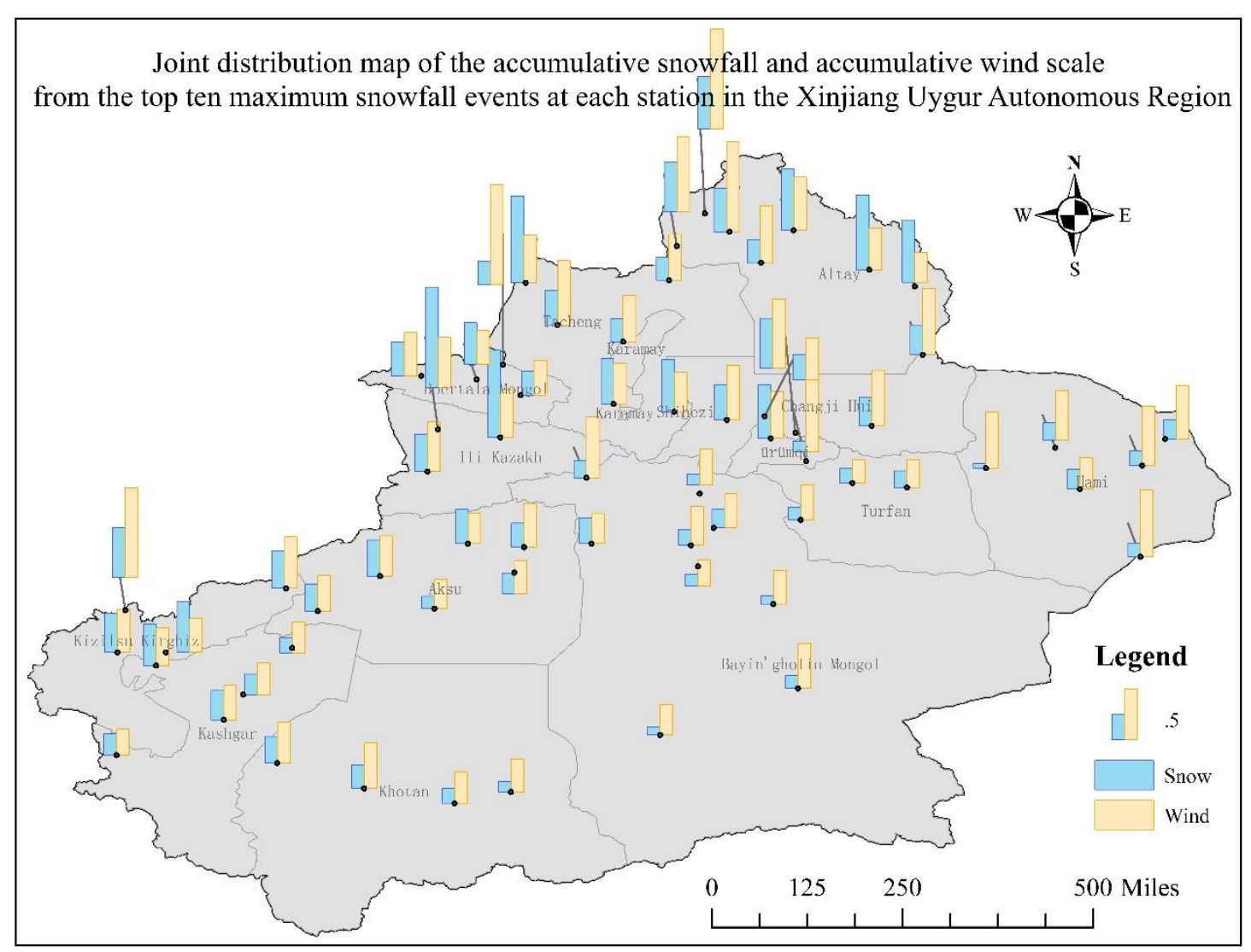

Figure 8. Joint distribution map of the accumulative snowfall and accumulative wind scale from the top ten maximum snowfall events at each station in the Xinjiang Uygur Autonomous Region.

The maximum wind scale after a heavy snowfall is of great concern because it determines the intensity of the snow drifting disaster. The authors generated the joint distribution map of the accumulative snowfall and maximum wind scale from the top ten maximum snowfall events at each station in the Xinjiang Uygur Autonomous Region, which is shown in Figure 9. From this, we can know that the maximum wind scale after a heavy snowfall is high in the northwestern Altay Prefecture, the western Bortala Mongol Autonomous Prefecture, the western Kizilsu Kirghiz Autonomous Prefecture, the eastern Ili Kazakh Autonomous Prefecture, the eastern Hami city, and the eastern Urumqi. Among the above regions, the snowfall in the Altay region, Ili Kazakh Autonomous Prefecture and Tacheng Prefecture is very heavy. So, these three regions are the hardest hit by the snow drifting disasters. The snowfall is not very heavy in the western Bortala Mongol Autonomous Prefecture, the western Kizilsu Kirghiz Autonomous Prefecture, the eastern section of Hami city, and the eastern neighborhoods in Urumqi. However, if heavy snowfall occurs, which provides plenty of snow particles, it's very easy to pose a snow drifting disaster. These are the key regions in terms of snow drifting disasters and deserve our focus. Other areas are not as peculiarly prone to this type of disaster. 
Joint distribution map of the accumulative snowfall and max wind scale from the top ten maximum snowfall events at each station in the Xinjiang Uygur Autonomous Region

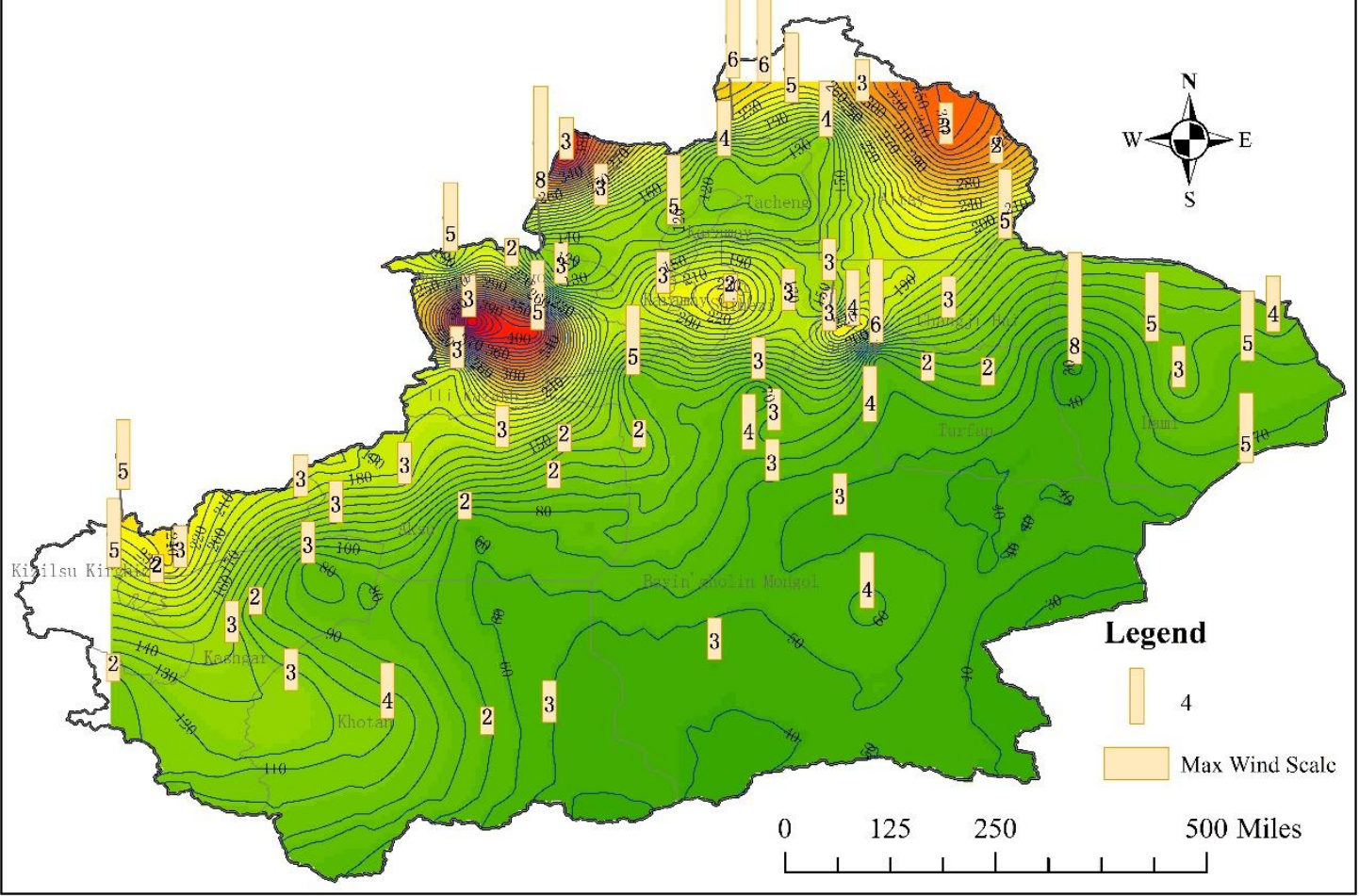

Figure 9. Joint distribution map of the accumulative snowfall and max wind scale from the top ten maximum snowfall events at each station in the Xinjiang Uygur Autonomous Region.

\section{Conclusions}

This study assessed the spatial distribution characteristics of wind and snowfall in the Xinjiang Uygur Autonomous Region of China based on the "Daily Data Sets of Climate Data for China International Surface Exchange Station (V3.0)". The following conclusions can be drawn from this analysis.

(1) The weighted accumulated wind scale is large in the northwest of Altay, the east and west of Hami and at the junction of Urumqi and Turpan. However, it's relatively small in other regions.

(2) The distribution map of the basic wind speed in winter at the 50-year reoccurrence period in the Xinjiang Uygur Autonomous Region was generated, which can be used in building structure design.

(3) The snowfall areas of the Xinjiang Uygur Autonomous Region are mainly in the north, and the heaviest snowfalls are in the Yili Kazak Autonomous and the northwestern Tacheng Prefectures.

(4) After heavy snowfall, the wind is very strong in northwestern Altay, the northwestern section of the Tacheng Prefecture and Urumqi city. So, the snowdrift disasters are very serious if they occur in these areas.

(5) After the top ten heavy snowfall events, the accumulative wind scale is high and the accumulative snowfall is large in the Altay Prefecture, the Bortala Mongol Autonomous Prefecture, and the Tacheng Prefecture of the northern Xinjiang, and the Kizilsu Kirghiz Autonomous Prefecture of the western Xinjiang.

\section{Acknowledgement}

The research reported herein was sponsored by the National Natural Science Foundation of China 
(Grant No. 51778381) and the Hebei Province Natural Science Fund (Grant No. D2016210008 and

349 Grant No. E2018210044). We would like to thank TopEdit (www.topeditsci.com) for English $350 \quad$ language editing of this manuscript.

\section{Competing interests}

352 The authors declare no competing interests.

\section{Reference}

354 National Meteorological Centre (2012). GB/T 28591-2012 Wind Scale. Beijing, Standards Press of 355 China. GB/T 28591-2012.

356 National Meteorological Centre (2017). GB/T 21984-2017 Short-Range Weather Forecast. Beijing, 357 Standards Press of China. GB/T 21984-2017.

358 Chen, H. and X. Fan (2009). "Some Extreme Events of Weather, Climate and Related Phenomena 359 in 2008." Climatic and Environmental Research 14(3): 329-340. (in Chinese with English Abstract) 360 Li, X., J. Zhu, Y. Jia, J. Liu, N. Li and F. Li (2007). "Formation process of extraordinarily serious 361 snowstorm and its induced damage in 2007 in Liaoning Province." Chinese Journal of Ecology(8): 362 1250-1258. (in Chinese with English Abstract)

363 Liu, J., X. Yao, Z. Han, P. Xie, L. Liu and P. Liu (2008). "Analysis on the cause and type of wind 364 blowing snow on Highways in Xinjiang." Highway(1): 25-27. (in Chinese)

365 Liu, W., X. Liu and H. Chen (2010). "On the Successful Shaping of Local Government Image in 366 Blizzard Disaster: an Example of Xinjiang Blizzard Disaster in 2010." Journal of Institute of 367 Disaster Prevention 12(2): 119-121+136. (in Chinese with English Abstract)

368 China Academy of Building Research (2012). Load code for the design of building structures, China 369 Architecture \& Building Press. GB 50009-2012.

370 Su, G. (2017). Research on Numerical simulation of Wind blowing snow at railway cut and disaster 371 prevention and control engineering Master, Lanzhou Jiaotong University. (in Chinese with English 372 Abstract)

373 Wang, T. (2009). Study on numerical simulation and prevention measures of the drifting snow 374 disaster along railway Master, Lanzhou University. (in Chinese with English Abstract)

375 Ying, C. (2007). Research on the Countermeasures of the Blowing Snow Hazards 376 on Highways Doctor, Jilin University. (in Chinese with English Abstract)

377 Zha, M., Z. Yu and H. Li (2012). "Study on the prevention against snow hazard for the highway 378 between Karamay and Tacheng." Journal of China \& Foreign Highway 32(4): 67-71. (in Chinese) 


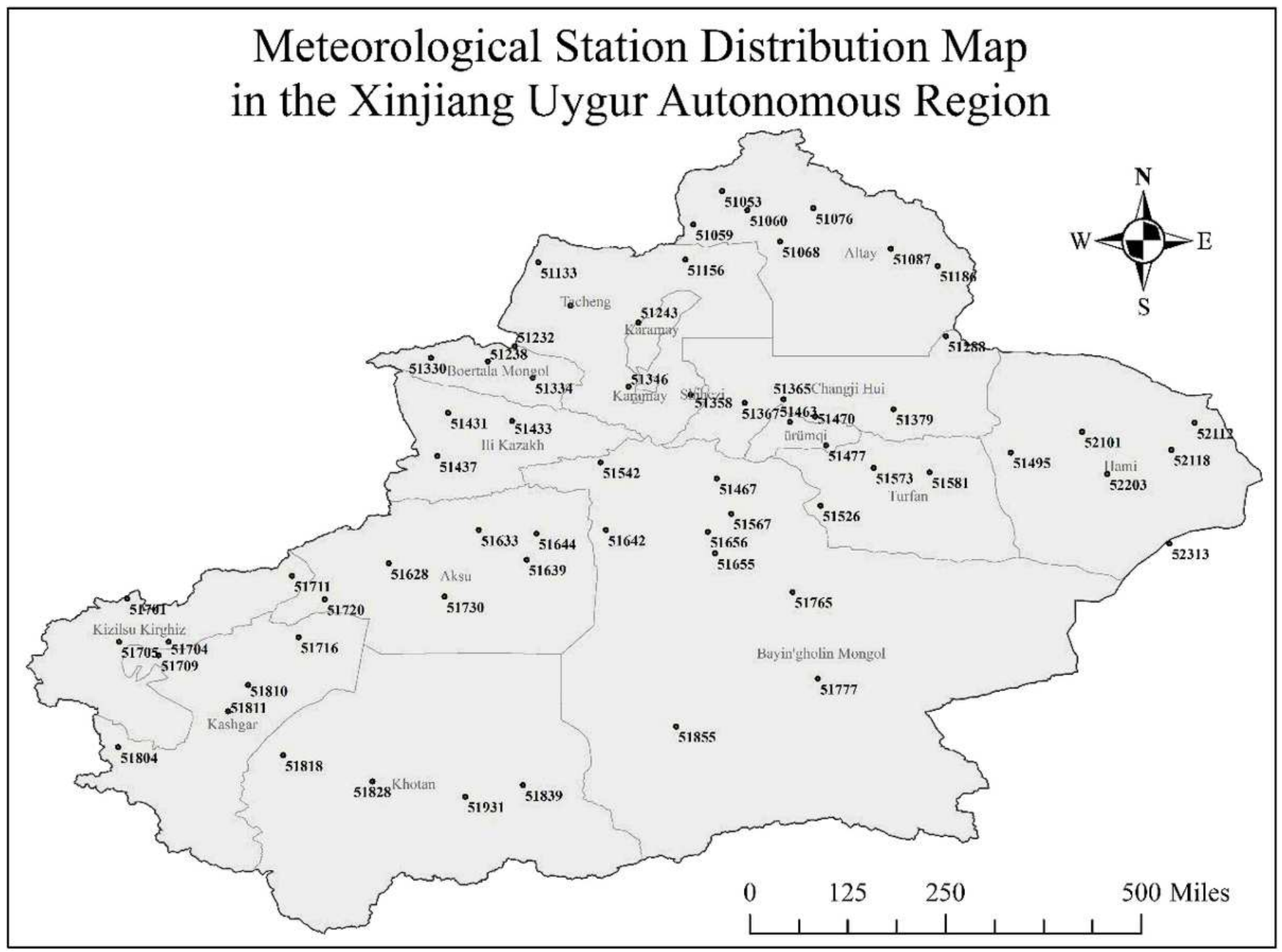

Figure 1

Meteorological station distribution map in the Xinjiang Uygur Autonomous Region. Note: The designations employed and the presentation of the material on this map do not imply the expression of any opinion whatsoever on the part of Research Square concerning the legal status of any country, territory, city or area o bbnhjr of its authorities, or concerning the delimitation of its frontiers or boundaries. This map has been provided by the authors. 


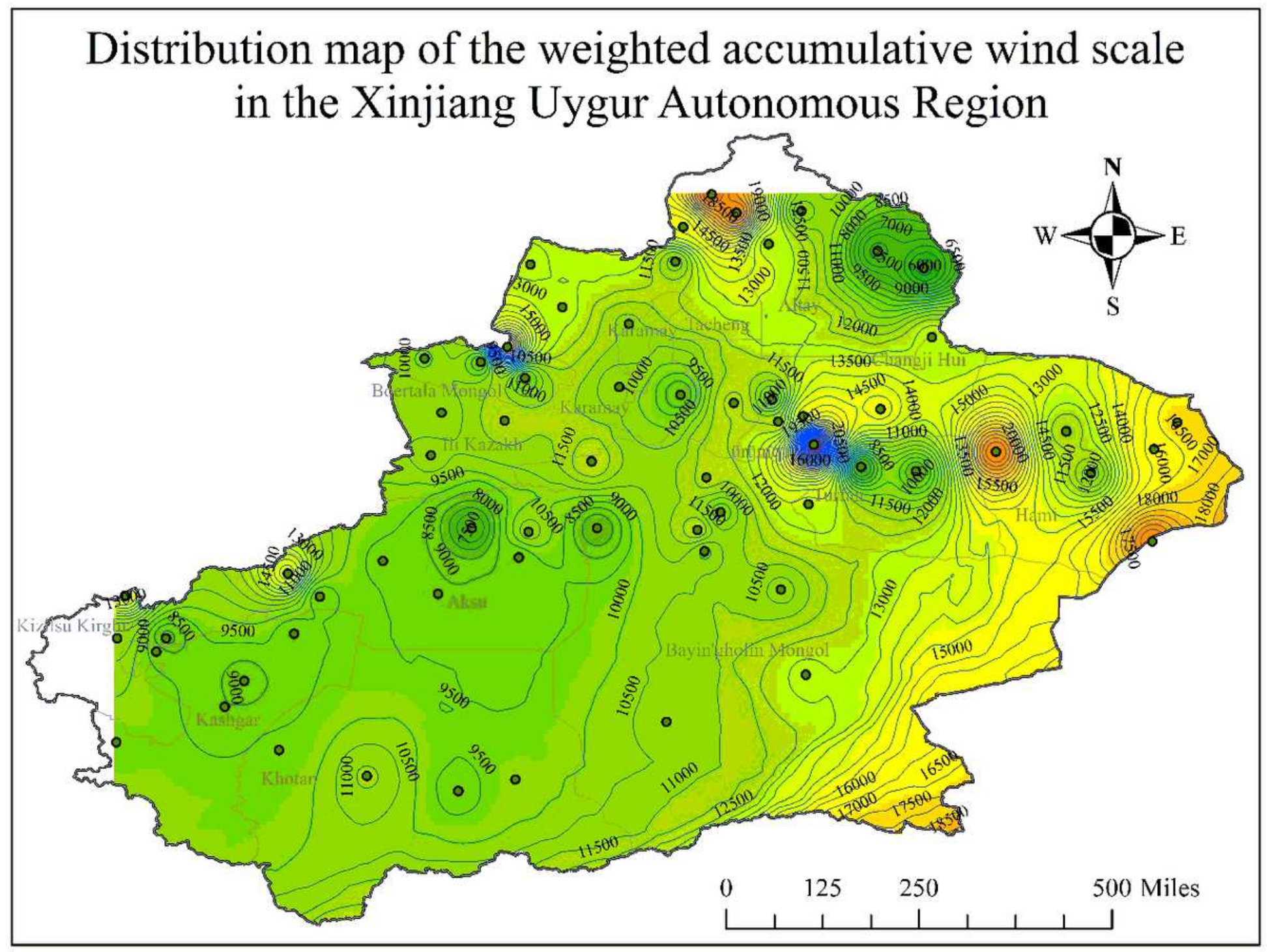

Figure 2

Distribution map of the weighted accumulative wind scale in the Xinjiang Uygur Autonomous Region Note: The designations employed and the presentation of the material on this map do not imply the expression of any opinion whatsoever on the part of Research Square concerning the legal status of any country, territory, city or area o bbnhjr of its authorities, or concerning the delimitation of its frontiers or boundaries. This map has been provided by the authors. 


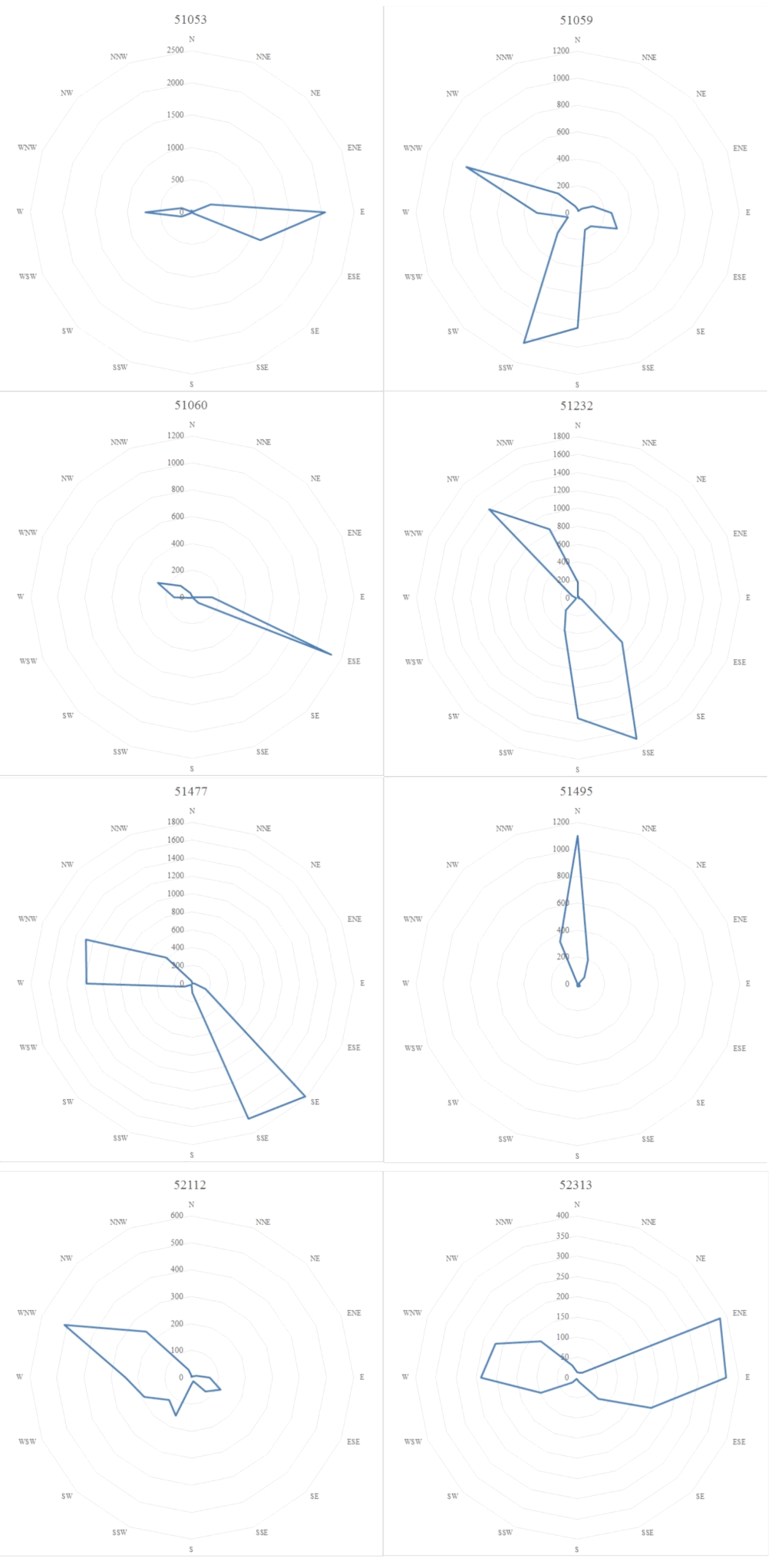

Figure 3

Maximum wind direction rose diagrams for some stations in the Xinjiang Uygur Autonomous Region 


\section{Distribution map of the basic wind speed in winter at the 50-year reoccurrence period in the Xinjiang Uygur Autonomous Region}
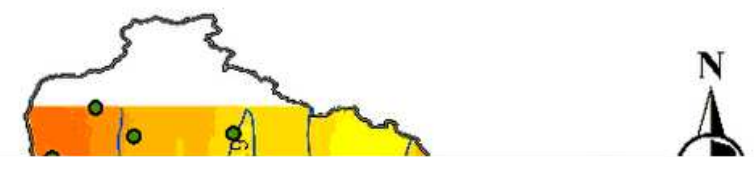

\section{Figure 4}

Distribution map of the basic wind speed in winter at the 50-year reoccurrence period in the Xinjiang Uygur Autonomous Region Note: The designations employed and the presentation of the material on this map do not imply the expression of any opinion whatsoever on the part of Research Square concerning the legal status of any country, territory, city or area o bbnhjr of its authorities, or concerning the delimitation of its frontiers or boundaries. This map has been provided by the authors. 


\section{Distribution map of weighted accumulative snowfall grade in the Xinjiang Uygur Autonomous Region}

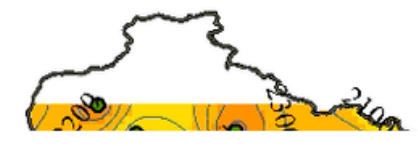

N

\section{Figure 5}

Distribution map of weighted accumulative snowfall grade in the Xinjiang Uygur Autonomous region Note: The designations employed and the presentation of the material on this map do not imply the expression of any opinion whatsoever on the part of Research Square concerning the legal status of any country, territory, city or area o bbnhir of its authorities, or concerning the delimitation of its frontiers or boundaries. This map has been provided by the authors. 
Distribution map of the accumulative wind scale from the top ten maximum snowfall days at all stations in the Xinjiang Uygur Autonomous Region

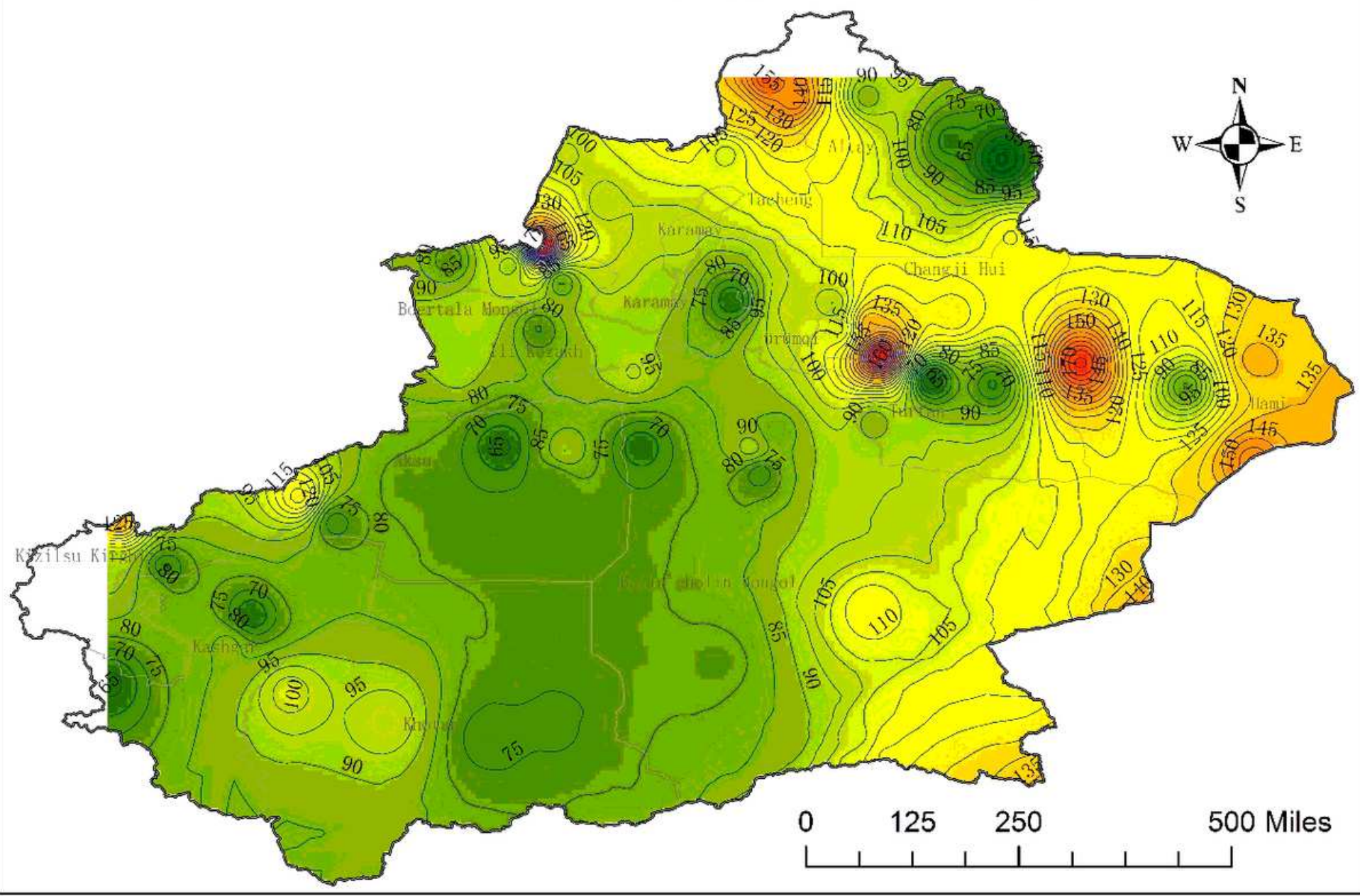

\section{Figure 6}

Distribution map of the accumulative wind scale from the top ten maximum snowfall days at all stations in the Xinjiang Uygur Autonomous Region Note: The designations employed and the presentation of the material on this map do not imply the expression of any opinion whatsoever on the part of Research Square concerning the legal status of any country, territory, city or area o bbnhjr of its authorities, or concerning the delimitation of its frontiers or boundaries. This map has been provided by the authors. 


\section{Joint distribution map of the total snowfall for the top ten maximum snowfall days and the accumulative wind scale for six days (including the day of snowfall) after the top ten maximum snowfall day at all stations in the Xinjiang Uygur Autonomous Region}

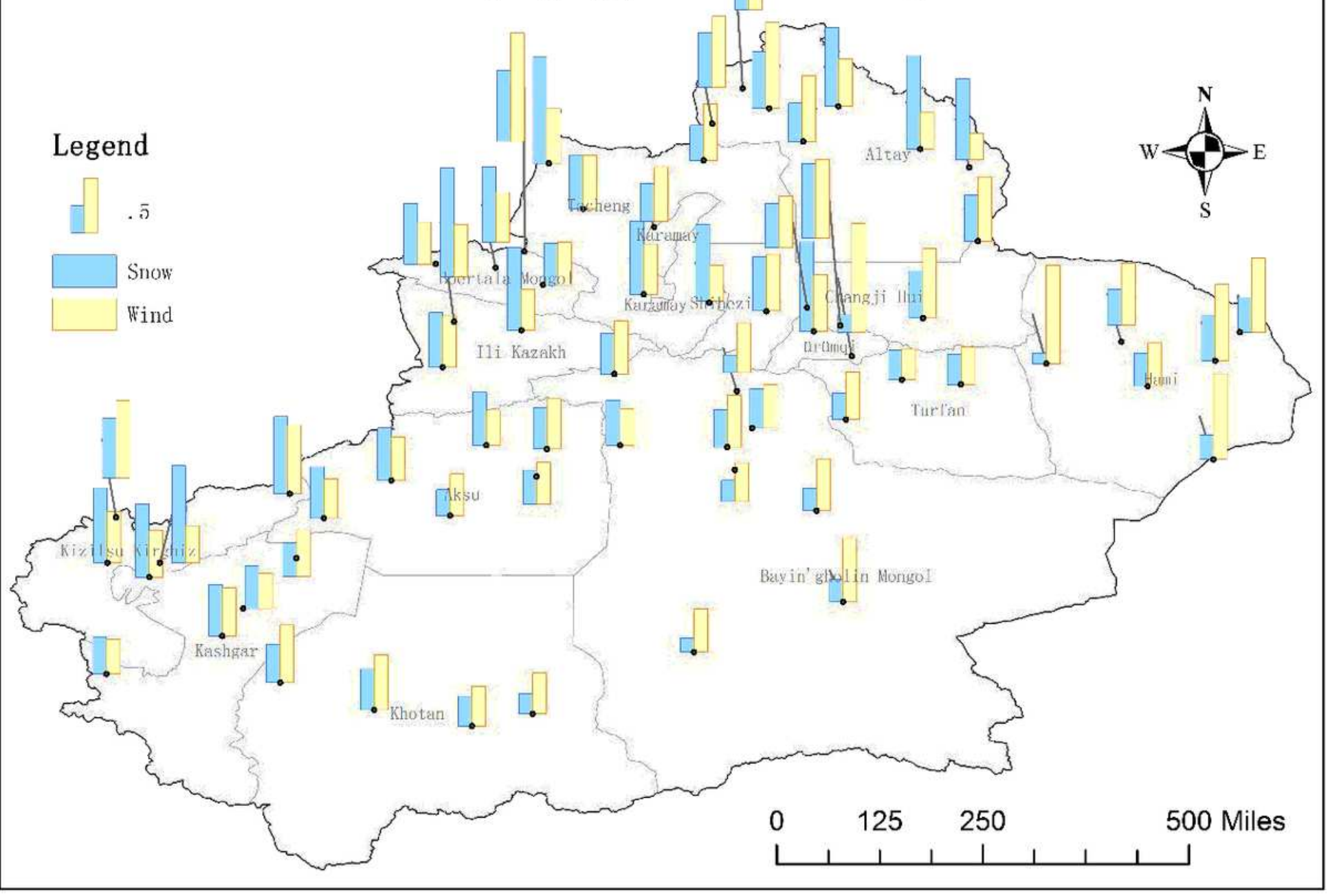

Figure 7

Joint distribution map of the total snowfall for the top ten maximum snowfall days and the accumulative wind scale for six days (including the day of snowfall) after the top ten maximum snowfall day at all stations in the Xinjiang Uygur Autonomous Region Note: The designations employed and the presentation of the material on this map do not imply the expression of any opinion whatsoever on the part of Research Square concerning the legal status of any country, territory, city or area o bbnhjr of its authorities, or concerning the delimitation of its frontiers or boundaries. This map has been provided by the authors. 
Joint distribution map of the accumulative snowfall and accumulative wind scale from the top ten maximum snowfall events at each station in the Xinjiang Uygur Autonomous Region
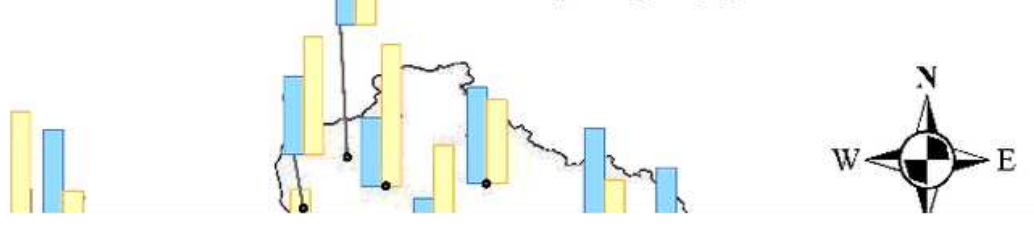

\section{Figure 8}

Joint distribution map of the accumulative snowfall and accumulative wind scale from the top ten maximum snowfall events at each station in the Xinjiang Uygur Autonomous Region. Note: The designations employed and the presentation of the material on this map do not imply the expression of any opinion whatsoever on the part of Research Square concerning the legal status of any country, territory, city or area o bbnhjr of its authorities, or concerning the delimitation of its frontiers or boundaries. This map has been provided by the authors. 




\section{Figure 9}

Joint distribution map of the accumulative snowfall and max wind scale from the top ten maximum snowfall events at each station in the Xinjiang Uygur Autonomous Region. Note: The designations employed and the presentation of the material on this map do not imply the expression of any opinion whatsoever on the part of Research Square concerning the legal status of any country, territory, city or area o bbnhjr of its authorities, or concerning the delimitation of its frontiers or boundaries. This map has been provided by the authors. 